Palimpsesto Vol. 11, № 19 (Julio-diciembre, 2021): 156-189

Universidad de Santiago de Chile, ISSN 0718-5898

Christian Matamoros Fernández

Universidad de Santiago de Chile

christian.matamoros@usach.cl

\title{
Pedagogía y política en la revista El Pizarrón: de la resistencia a la renovación (1978-1990)
}

\section{Pedagogy and Politics in the Journal El Pizarrón: from Resistance to Renewal (1978-1990)}

\begin{abstract}
Resumen
En el presente artículo se estudia la revista El Pizarrón, la que es analizada a partir de la lectura de sus ediciones y de entrevistas a integrantes de su comité editorial. El Pizarrón representó la publicación educacional más importante de la oposición a la dictadura de Augusto Pinochet y sus motivaciones pedagógicas, políticas y sindicales se vincularon al proceso de renovación ideológica que experimentó el socialismo chileno durante la década de 1980. Lo anterior se tradujo principalmente en un giro dado por la revista respecto al rol que el Estado y los privados debían asumir en la administración educacional, como también respecto a la estructura organizativa más apropiada para los docentes chilenos.
\end{abstract}

Palabras claves: Renovación socialista, revistas pedagógicas, renovación pedagógica, historia social de las ideas, historia de la educación.

\begin{abstract}
This article studies the journal El Pizarrón, which is analyzed from the reading of its editions and interviews with members of its editorial committee. El Pizarrón represented the most important educational publication of the opposition to the Augusto Pinochet dictatorship and its pedagogical, political and union motivations were linked to the ideological renewal process that Chilean socialism experienced during the 1980s. The above was translated mainly in a turn given by the magazine regarding the role that the State and the private sector should assume in the educational administration, as well as regarding the most appropriate organizational structure for Chilean teachers.
\end{abstract}

Keywords: Renewal Socialist, Pedagogical Journals, Pedagogical renewal, social history of ideas, history of education. 


\section{Introducción}

El Pizarrón fue una revista publicada durante la dictadura militar chilena con fines políticos y pedagógicos, teniendo como destinatarios principales a los profesores del sistema escolar. Durante todo el periodo en que se publicó (1978-1990) la revista dio cuenta de su oposición a la dictadura, lo que se expresó mediante posicionamientos políticos y críticas a las políticas educativas impuestas, de la mano con planteamientos identificados con la renovación pedagógica.

Los objetivos políticos y pedagógicos de El Pizarrón la sitúan como una revista de un carácter reflexivo, pero con un claro posicionamiento político, distanciándose de publicaciones de tipo literarias o académicas, las que por lo general no adoptan un posicionamiento político militante o lo hacen de forma secundaria (Tarcus, 2004). El Pizarrón en cambio, intentó impulsar al profesorado a posicionarse críticamente. Su componente político-pedagógico fue resultado del encuentro de trayectorias individuales (investigadores de la educación y actores destacados durante la Unidad Popular) y colectivas (militancias partidarias, participación en Centros de Estudios, etc.) de quienes le dieron vida. Nuestra hipótesis, sostiene que la revista representó un referente a nivel pedagógico del proceso conocido como "renovación socialista", el que, alejado de las posiciones de los sectores tradicionales de izquierda y maximalistas, prefiguró gran parte de las políticas educacionales que se transformarían en hegemónicas hacia fines de los años '80s y se implementarían en los gobiernos posdictatoriales.

La materialización de esa renovación socialista fue de la mano con las ideas de la llamada "renovación pedagógica", caracterizadas por la crítica a la escuela tradicional, la defensa de una escuela democrática y cívica, dando espacio a corrientes pedagógicas transformadoras y al análisis riguroso de las políticas educativas oficialistas (Esteban, 2016). Estas ideas habían sido defendidas por algunos integrantes del comité editorial de El Pizarrón desde fines de los '60s, de la mano con posiciones marxistas heterodoxas. Otros integrantes, en cambio, sostuvieron posiciones más distantes a la renovación pedagógica, ancladas en interpretaciones marxistas más tradicionales y maximalistas. Si los primeros se identificaron con el Movimiento de Acción Popular Unitaria (MAPU), los segundos con el Partido Socialista, pero todos se hicieron parte durante la dictadura de la renovación socialista y abandonaron cualquier tipo de posicionamiento pedagógico vinculado a una interpretación marxista ortodoxa. Esto fue especialmente destacado, como veremos, en la pérdida de la asignación al Estado de un rol destacado en las transformaciones educacionales, cuestión que coincidió de muy buena forma con los cambios experimentados por la renovación socialista.

Durante doce años, la revista fue un importante medio de difusión opositor dirigido a los educadores. Su existencia fue de la mano con la reorganización de los docentes y la activación de los sectores de la oposición política. A ellos comenzó a llegar El Pizarrón, y éstos la utilizaron como una herramienta para la discusión y el fortalecimiento de las organizaciones. Si bien es cierto, la revista no emanó directamente de los maestros organizados, sino, al menos desde 1979, de un grupo de investigadores sobre temáticas educativas, estuvo directamente vinculada y con una no menor influencia, a las organizaciones docentes durante toda su existencia, logrando pasar de algunos cientos de ejemplares repartidos entre los profesores de la capital, hasta ser distribuida por miles entre los sectores más activos a nivel nacional. Lo anterior permite circunscribir la función de este grupo de intelectuales dentro de lo que Moyano y Lozoya (2019) han definido 
como "basistas", por su intento por desarrollar la construcción del conocimiento desde los sujetos populares mismos.

Tradicionalmente las revistas han tenido una consideración historiográfica en tanto fuentes que permiten acceder a determinados sujetos, instituciones o miradas. En cambio, desde hace un tiempo, principalmente por la historia intelectual, han venido desarrollándose análisis que las consideran como un objeto propio de investigación y no como una fuente auxiliar a esta. Desde esa perspectiva posicionaremos nuestro análisis de El Pizarrón, siguiendo las propuestas metodológicas realizadas por Pita y Grillo (2015) quienes proponen en el estudio de revistas no sólo considerar los contenidos temáticos de estas, sino también su materialidad (formato, tipo de letra, símbolos, composición gráfica, etc.) y al grupo intelectual dedicado a su edición, como también a las redes intelectuales de las que estos formaban parte. En ese sentido, la presente investigación se enmarca en los posicionamientos de lo que se ha denominado como historia social de las ideas, la que se ha centrado en el estudio de las ideologías y la difusión de las ideas (Darnton, 2010).

Para el caso chileno, existen diversos estudios sobre revistas, destacándose un grupo de investigaciones que se emparenta con este artículo, pues se han enfocado en las publicaciones vinculadas al proceso de renovación ideológica que experimentó el socialismo chileno. Así, por ejemplo, se ha estudiado la revista Convergencia, principal publicación partidaria de la renovación socialista (Santoni, 2013); también se han analizado algunas publicaciones de centros académicos vinculados a ese cambio ideológico como la revista Proposiciones (Moyano y Mella, 2018). Además, se ha abordado la relación entre dichas publicaciones y la construcción de liderazgos políticos (Moyano, 2009) y se han investigado revistas de difusión masiva de la órbita socialista renovada como APSI (Orrego, 2002; Muñoz, 2015).

Respecto a revistas vinculadas al mundo educacional, su estudio a nivel europeo y latinoamericano ha sido secundario, pero en los últimos años han aumentado la cantidad de investigaciones. A esto han contribuido los intentos por articular las investigaciones internacionales sobre revistas pedagógicas, ya sea en libros (Hernández, 2013) o en dossiers de revistas científicas de acceso abierto como Temas em Educação (2015) o Aula (2021).

En el caso chileno, si bien han existido estudios sobre revistas del mundo educativo estas han sido consideradas principalmente como fuentes, especialmente para publicaciones de las primeras décadas del siglo XX (Silva, 2016, 2017; Hernández, 2018; Martínez, 2020; Hernández y Zamorano, 2016; Hernández, 2018). Por otro lado, Camila Silva (2010) ha estudiado el rol jugado por la institucional Revista de Educación durante el gobierno de Frei Montalva. Jaime Caiceo (2021) se ha centrado en la producción de los Anales de la Facultad de Educación de la Universidad Católica, en su etapa de 1979 a 1992. Las revistas escolares existentes en la biblioteca del Museo de la Educación han sido estudiadas por Elizabeth Mejías (2019), dando cuenta que representaron espacios donde el estudiantado ponía en tensión la disciplina escolar. Para el final hemos dejado un pequeño artículo de Iván Núñez (1978) que representa el puntapié para los estudios sobre revistas educacionales, pero lamentablemente el difícil acceso a ese escrito no ha permitido tomar en cuenta sus planteamientos por investigaciones recientes.

En la presente investigación compartimos la apreciación de José María Hernández (2013) respecto a que la prensa pedagógica presenta una oportunidad documental especial para el historiador de la educación, sobre todo desde una lectura social. En esa línea, abordaremos un estudio de una prensa para comprender el objetivo político buscado por esta. En el caso de $E l$ Pizarrón, han existido algunos trabajos que han tomado en cuenta sus contenidos, tratándola como una fuente documental (Espinoza y González, 1993; Núñez, 1990; Cerda, Silva y Núñez, 
1991) y otros que, mediante entrevistas, han destacado a los integrantes de su comité editorial como parte del movimiento de educadores (Reyes, 2005).

Para lograr una panorámica suficiente del periodo de publicación de la revista, hemos revisado diversas bibliotecas y numerosos archivos personales de profesores. Para complementar esta revisión, hemos realizado entrevistas a educadores que integraron la revista desde 1979 en adelante y a profesores del periodo que tuvieron acceso a ella. Estas entrevistas se enfocaron en los posicionamientos políticos de la revista y en la distribución alcanzada. De esta forma operacionalizaremos la propuesta de Pita y Grillo (2015), analizando los cambios en los contenidos temáticos de la revista, su materialidad estética y física, y al grupo intelectual que editó la publicación, tanto como a sus redes y el alcance que tuvo en el profesorado.

\section{Las publicaciones del mundo educacional chileno}

El ámbito educacional se ha presentado particularmente propicio para la publicación de revistas y periódicos, pues su dinámica propia y objetivos ha incentivado publicaciones de diverso carácter: formativas, alfabetizadoras, institucionales, gremiales, pedagógicas, estudiantiles, políticas, etc. Los docentes chilenos contaron con publicaciones realizadas por ellos o dirigidas hacia ellos durante toda la vida republicana. Tempranamente surgieron publicaciones de tipo institucional, como El Monitor de las Escuelas Primarias (1852-1864), la Revista de Instrucción Primaria (1886-1920), la Revista de Educación Primaria (1921-1928), la Revista de Educación (1928-2021) y la Revista de Enseñanza Normal (1951-1953).

Las organizaciones docentes publicaron una gran cantidad de boletines y periódicos, especialmente desde la década de 1920 en adelante. Algunos pocos tuvieron un alcance nacional, como el Boletín de la Sociedad Nacional de Profesores o Unidad de la Unión de Profesores de Chile, y muchos otros fueron iniciativas de secciones comunales o provinciales. En la mayoría de las ocasiones trataron temáticas sindicales, reivindicativas, de contingencia política y educativa, además de cuentos y poemas. Menormente, incluyeron temáticas pedagógicas o representaron al profesorado militante de determinados partidos como Trinchera, editada por los profesores socialistas en las décadas de 1930 y 1940, o Trabajadores de la Enseñanza publicado entre 1932 y 1934 por la Federación de Maestros identificada con el Partido Comunista.

Pequeñas agrupaciones docentes también editaron revistas no exclusivamente gremiales. Entre estas estuvo Nervio, la que apareció entre 1934 y 1936 en la ciudad de Curicó. Bajo la responsabilidad de un grupo de educadores e intelectuales radicados en esa ciudad y Santiago, sus páginas defendieron postulados "funcionalistas", "biologicistas-organicistas", sindicalistas, antipartido, socializantes y pacifistas (Núñez, 1986, 2013) y también los derechos de la mujer (Salinas, 2017). En una línea similar, combinando preocupaciones pedagógicas y gremiales, se publicó Renovación (1946-1960), editada por la Comisión de Renovación Gradual de la Educación Secundaria; Educación Moderna (1950-1951), bajo la dirección de Aida Parada; Avanzada. Órgano de la Asociación de Profesores de Escuelas Experimentales (1959); y Educadores del Mundo (1956-1973) vinculada a la órbita soviética.

Este último grupo de revistas es el que representa la tradición en la que se puede circunscribir El Pizarrón, al incluir motivaciones políticas, pedagógicas y gremiales, las que por lo general han estado articuladas en torno a un grupo de intelectuales, docentes de aula o 
especialistas en educación, los que buscan disputar los sentidos de las prácticas y políticas educativas.

Bajo la dictadura militar (1973-1990) las publicaciones del mundo educativo fueron escasas durante los primeros años. El clima de persecución política permitió que solamente circularan publicaciones vinculadas al régimen o del mundo estrictamente académico. Entre las primeras estuvo la Revista de Educación, portavoz del Ministerio de Educación, y publicaciones menores y ocasionales del Colegio de Profesores (CP), organización creada por la dictadura en 1974. Además, entre 1987 y 1989 el profesorado que respaldaba al régimen publicó la revista $E l$ Profesor, la que buscó agrupar al magisterio de esa tendencia.

Por su parte, desde el mundo académico el Centro de Investigación y Desarrollo de la Educación, CIDE, continuó publicando mensualmente Cuadernos de Educación, dirigida a académicos y profesores, centrada en artículos de análisis de las políticas educacionales, metodologías participativas e innovadoras, donde ocasionalmente aparecieron reflexiones sobre la organización gremial o la renovación pedagógica. El mismo CIDE también continuó publicando, dos veces al año, los Resúmenes Analíticos en Educación dirigidos principalmente a especialistas.

Por la senda de la oposición docente, desde el momento en que se inició el proceso de reorganización sindical emergieron las publicaciones en Santiago y en las principales ciudades. Esa reorganización se cobijó en las instancias facilitadas por la iglesia católica y las actividades culturales, de ahí que una de las primeras publicaciones emergió de la Agrupación Cultural de Profesores Pedro Aguirre Cerda (ACUPAC), compuesta por docentes de la zona sur de Santiago. El Boletín ACUPAC vio la luz en 1978 y a mediados del año siguiente le siguió La Campana. Boletín de los Educadores, vinculado a la naciente Coordinadora Metropolitana de Educadores (CME). Desde ese momento, comenzaron a surgir diversos boletines artesanales, clandestinos en la práctica, en algunos "zonales" de la CME y de la Coordinadora de profesores regional Concepción durante 1980-1981 (Cisterna, 2019). Mucho más moderado, contando con autorización legal y en un formato un tanto más profesional, en 1981 vio la luz la revista Nosotros los maestros, editada por el Club Deportivo, Cultural y Recreativo del Magisterio de San Miguel, también en la zona sur de la capital. Por otro lado, desde 1986 a 1990, el sindicato de trabajadores municipales de La Florida, compuesto mayormente por profesores, publicó la revista $R \hat{u} p u$, donde se incluyó información gremial y política, actividades y creaciones literarias de los mismos docentes.

Finalmente, con el nacimiento de la Asociación Gremial de Educadores de Chile (AGECH), a fines de 1981, se abrió un nuevo espectro de publicaciones, debido principalmente al carácter opositor de la AGECH y su rápida estructuración nacional. Su primera iniciativa de carácter nacional fue Micronoticias, editado en Santiago durante 1982, la que fue reemplazado entre 1985 y 1987 por La Opinión. En 1984 se publicaron varios números del Boletín Internacional $A G E C H$, mientras que ya desde agosto de 1982 aparecieron boletines locales, especialmente en la provincia de Concepción y en los comunales de esa zona. A nivel metropolitano se publicó Magisterio durante 1985 y 1986, mientras que el Departamento de Profesores Jóvenes de Santiago publicó Profe y Tiza a fines de 1985, los que tuvieron escasa continuidad y una fabricación muy artesanal.

Sin embargo, la iniciativa revisteril más importante de la AGECH fue Signos, una revista autodefinida como "de Educación y Cultura", la que alcanzó a editar 7 números entre 1984 y 1985. Signos se emparenta de alguna u otra manera con el grupo de revistas que combinaron contenidos políticos, gremiales y pedagógicos, pero a pesar de ser responsabilidad de una entidad 
eminentemente gremial, tuvo un carácter más académico, con escasas contribuciones de docentes de aula o asociados a la AGECH. En cambio, reprodujo varios artículos aparecidos en otras revistas como Chile América, Araucaria, entre otras. En Signos escribieron investigadores asociados al CIDE, al PIIE (Programa Interdisciplinario de Investigaciones en Educación), a Universidades y otras instituciones, como Cristián Cox, Abraham Magendzo, Loreto Egaña, Iván Núñez, Salomón Magendzo, Consuelo Gazmuri, Olga Poblete, Fernando Castillo Velasco, Humberto Giannini, Roberto Munizaga, Aníbal Palma, Andrés Sabella, Ximena Valdés, Julieta Kirkwood, entre otros.

En marzo de 1986 asumió la primera directiva democráticamente electa del Colegio de Profesores, la que a nivel nacional no tuvo muchas iniciativas en cuanto a publicaciones. En noviembre de ese año editó el boletín Magisterio, de escasa continuidad, y recién a fines de 1989 vio la luz El Educador, el que se sostuvo durante la década siguiente.

Bajo este contexto, El Pizarrón representó la revista educacional con mayor persistencia durante la dictadura, combinando temáticas gremiales, políticas y pedagógicas.

\section{El Pizarrón de la Resistencia}

En 1978 el MAPU, partido político de izquierda nacido en 1969 como una escisión de jóvenes rebeldes de la Democracia Cristiana (DC), y que se encontraba en la ilegalidad, dio vida a un órgano de prensa clandestino destinado a los profesores opositores, el que se llamó El Pizarrón de la ${ }^{\circledR}$. La letra $\mathrm{R}$ encerrada en un círculo representaba el concepto de resistencia, el que tras el golpe militar de 1973 fue enarbolado por el MAPU como la táctica para enfrentar a la dictadura, la que fue compartida con el otro sector del partido, escindido durante la Unidad Popular, llamado MAPU-Obrero Campesino (MAPU-OC). ${ }^{1}$

El líder del MAPU, Oscar Garretón, debió salir al exilio, por lo que al interior del país la conducción partidaria recayó en Carlos Montes, egresado de economía. Con duras condiciones represivas, el partido publicó desde 1975 el periódico Venceremos y desde 1978 De Frente, al que se sumó Letras de emergencia, medio cultural de artistas populares. Esto fue manifiesto de la alta importancia que el MAPU le asignaba a la publicación de prensa directamente partidaria o de algunos de sus "frentes", buscando construir poder mediante la influencia social. De esta forma, en el mundo de los educadores también se buscó levantar un medio de prensa específico.

El MAPU contó con un número pequeño de profesores y profesoras, minoritario frente a otras fuerzas opositoras como el Partido Comunista (PC) o el Partido Socialista (PS), pero muy destacados en cuanto a sus planteamientos pedagógicos alternativos y transformadores. La experiencia en Chile del trabajo del educador popular brasileño Paulo Freire durante el gobierno del DC Eduardo Frei Montalva fue especialmente recepcionada por los profesores mapucistas, varios de los cuales trabajaron con él en los procesos de alfabetización campesina. Algunos de estos asumieron importantes cargos durante el gobierno de Salvador Allende, especialmente los que provenían desde la Universidad Católica (UC), como Carlos Eugenio Beca en la jefatura de

\footnotetext{
${ }^{1}$ La división fue entre un sector mayoritario que mantuvo el nombre MAPU, de corte marxista leninista, más radicalizado, y un sector, el MAPU-OC, con una mirada más moderada, cercana al Partido Comunista.
} 
Educación de Adultos de la Subsecretaría de Educación ${ }^{2}$ o Rodrigo Vera, uno de los Coordinadores Generales del Centro de Perfeccionamiento, Experimentación e Investigaciones Pedagógicas (CPEIP) desde donde dio vida a los Talleres de Educadores, los que consistían en una modalidad participativa de perfeccionamiento para los trabajadores de la educación, buscando superar las prácticas autoritarias (Vera, 1972). Esta línea era claramente deudora de las propuestas de Freire, opuesta al burocratismo impuesto por otros sectores del gobierno, como el Partido Radical (PR), y a las transformaciones gradualistas del PC.

Jorge Olivo, mapucista y profesor de castellano, recuerda así a los educadores del MAPU:

éramos pocos, pero existíamos. Con Rodrigo Vera y otros más, se planteaban cosas alternativas, cuestionamientos, los Talleres de Educadores. Toda una construcción distinta de la escuela. En ese aspecto, el MAPU tenía una mirada crítica y estuvo en línea de lo que eran los cambios, pero los otros partidos eran más tradicionales [...] El grueso de los cuadros tenía posiciones críticas en educación. (Entrevista, 27 de julio de 2018)

La escasa presencia numérica del MAPU en los profesores hizo destacar aún más a sus militantes intelectuales. ${ }^{3}$ En las elecciones del Sindicato Único de Trabajadores de la Educación (SUTE) en 1972 sus candidatos nacionales lograron 676 preferencias, solo superando a la Izquierda Cristiana, y muy por debajo de las otras fuerzas de izquierda, donde los candidatos del MIR (Movimiento de Izquierda Revolucionaria) lograron 1.461 votos, los comunistas 6.175 y los socialistas 11.888 (Cox, 1985).

Tras el golpe de Estado, la presencia de esos educadores persistió, aunque con exilios y exoneraciones, siendo el PIIE uno de los principales focos de articulación. Formado en 1971 en la Universidad Católica, el PIIE representó un importante espacio para la investigación educacional, pero que después de 1973 se vio sumamente limitado hasta que en 1977 fue suprimido como espacio académico de la UC, por lo que ese mismo año fue acogido en la recién fundada Academia de Humanismo Cristiano. En el sindicalismo docente de la década de los '80s los mapucistas fueron pocos, pero estuvieron presentes. Así desde el MAPU se destacaron Jorge Olivo, Mercedes Jeréz, Jorge Venegas, Pedro Robles y Alfonso Pastene, mientras que el MAPUOC contó con Eduardo Osorio, Samuel Bello, Lucía Rojas, Luis Gauthier y René Aucapán.

De esta forma, en el MAPU se instaló la necesidad de aprovechar el potencial intelectual de ese pequeño grupo de militantes vinculados a educación. Así, en el segundo semestre de 1978 nació, con el nombre de El Pizarrón de la $R$, una revista clandestina vinculada orgánicamente al MAPU y dirigida al profesorado militante o con el objetivo de atraer a nuevos docentes al

\footnotetext{
${ }^{2}$ Beca fue presidente de la Federación de Estudiantes de la Universidad Católica entre 1964-1965, y en 1968 se tituló como profesor de filosofía. Ese mismo año, durante la reforma de esa Universidad, asumió como ayudante del Vicerrector académico recién nombrado, el profesor de filosofía brasileño Ernani María Fiori.

${ }^{3}$ Algunos destacados educadores mapucistas fueron María Antonieta Saa, Rodrigo González y Raúl de la Puente, quienes desde ambas corrientes del MAPU participaron de los programas de alfabetización campesina durante los gobiernos de Frei Montalva y Allende, ejercieron como profesores universitarios o participaron sindicalmente. Además, varios investigadores del CIDE fueron militantes o cercanos al MAPU, como Sergio Martinic, Pedro Mendizábal, Carmen Sotomayor y Juan Eduardo García Huidobro (Valenzuela, 2011), mientras que en el PIIE estuvieron Ricardo Hevia y Beatriz Ávalos. Finalmente, otros militantes tuvieron una destacada participación en procesos de educación popular y educación de adultos, a pesar de no haber estudiado pedagogía, como Francisco Vio Grossi (abogado) y Adriana Delpiano (trabajadora social), secretario general y directora del Centro de Educación de Adultos para América Latina (CEAAL).
} 
partido. Según el testimonio de Rodrigo Vera, uno de los principales responsables de la revista en el periodo siguiente, El Pizarrón de la $R$ estaba dirigido directamente por Carlos Montes, pero por las condiciones de clandestinidad desconoce quienes más formaron parte de su elaboración (Entrevista, 27 de septiembre de 2021). Otro de los responsables de la revista desde el año siguiente, Ricardo Hevia, recuerda que él solo conoció "de oídas" El Pizarrón de la R, pero nunca lo leyó, el que habría tenido un carácter muy panfletario (Entrevista 12 de octubre de 2021). El distanciamiento de este primer periodo de la revista respecto a los siguientes se manifiesta en que, de todos los números revisados, todos posteriores a 1978, en ninguno se menciona algún artículo del periodo de la "resistencia".

Durante este primer periodo fundacional de 1978, se publicaron cerca de 4 números, a los cuales en esta investigación no hemos podido acceder. Según los testimonios de Vera y Hevia, en 1978 la circulación fue restringida, debido especialmente a las duras condiciones de clandestinidad.

El nacimiento de la revista se vivió en momentos donde recién daban sus primeros pasos los intentos de rearticulación docente, buscando superar el temor, especialmente desde los Departamentos de Capacitación Laboral (DECAL) de la iglesia. Allí el MAPU tenía alguna presencia, pero escasas posibilidades de crecimiento, cuestión distinta al potencial que representaban los intelectuales de la educación, para eso se necesitó que la revista no mantuviera su vinculación partidaria, sino que se abriera a otras fuerzas.

A fines de 1979, Carlos Montes entregó la dirección de esta artesanal revista a Rodrigo Vera y Ricardo Hevia, con lo cual esta mantuvo determinadas concepciones políticas, pero dejó de ser un órgano partidario. Esto daría paso a una nueva etapa que es en la que aquí nos concentraremos.

\section{La conformación intelectual de El Pizarrón}

En 1979 la revista dejó de ser el órgano del MAPU y, si bien, Vera y Hevia provenían de las filas mapucistas, abren la revista a un espectro político un tanto más amplio y, coherente con eso, eliminan la "R" del título de la revista, dejando atrás el periodo de la resistencia. Vera recuerda que fue el mismo Carlos Montes quien le entregó la responsabilidad de continuar con la revista, "con eso le cambiamos su línea editorial y su orientación".

Con esta apertura limitada, se invitó a participar a un personaje clave en la historia de la educación chilena, el profesor de historia Iván Núñez Prieto, quien provenía de las filas socialistas, habiendo sido Superintendente de Educación durante la Unidad Popular y miembro del Comité Central del PS al momento del golpe de Estado. Esta apertura no significó que la revista dejara de tener una identificación política, pues sus integrantes comenzaron desde esos años a identificarse con el sector del socialismo que llevó a cabo una renovación política hacia posiciones de centro, lo que ha sido denominado como la "renovación socialista". Esta línea comenzó a estructurarse desde 1979 con la división del PS, y de diversas formas fue adhiriendo el MAPU, el MAPU-OC y la Izquierda Cristiana bajo una suerte de coalición política llamada Convergencia Socialista, la que con el tiempo se estructuró en torno al llamado PS-Núñez. ${ }^{4}$

\footnotetext{
${ }^{4}$ Fracción del PS en torno a la que se fue estructurando la renovación socialista. Debe su nombre a Ricardo Núñez, uno de los líderes de esa fracción.
} 
Vera y Hevia se habían formado como filósofos en la Universidad Católica y eran dos intelectuales expertos en temáticas educativas. Rodrigo Vera Godoy era un poco mayor y obtuvo su doctorado en filosofía en Lovaina en 1969. Si bien, la revista nunca tuvo un director propiamente tal, consideramos que Vera representó el principal articulador del grupo que dirigía El Pizarrón, el que, repetimos, siempre funcionó como un comité de pares, carente de verticalidad. Rodrigo Vera es mencionado inclusive por Carlos Montes como uno de los principales referentes del grupo fundacional del MAPU en la UC. Siendo profesor en esa Universidad, sus clases fueron uno de los gatillantes de los jóvenes rebeldes que dividieron aguas con la DC (Valenzuela, 2011, p. 161). Vera comenzó a ejercer la docencia en la UC durante los '60s, pasando a ser profesor en el Departamento de Filosofía, desde donde se comenzó a desarrollar una alta valoración por la educación como senda para responder a las inquietudes humanas en una sociedad llena de contradicciones (Celis, 1982). En esos años la filosofía se venía articulando de muy buena forma con la historia, la sociología y la educación, bajo la tutela de autores como Freire, Althusser, Marx, Buber, Bergson, Sartre, etc. Ricardo Hevia recuerda que conoció a Rodrigo Vera en "un curso de Lukács" en que este fue su profesor, cuya temática habría sido fundamental para su formación (Entrevista 12 de octubre de 2021). Posteriormente se habría continuado identificando con autores marxistas heterodoxos del llamado marxismo occidental. ${ }^{5}$ El profesor Jorge Olivo recuerda que esa característica también estuvo en la revista:

El Pizarrón reunía a gente del partido [MAPU], gente de izquierda, gente que planteaba una mirada alternativa que arranca un poco de Paulo Freire, con una mirada gramsciana, una mirada distinta de Althusser con respecto a los aparatos ideológicos del Estado. Ahí estaba todo lo que eran prácticas alternativas, miradas diferentes. Rodrigo Vera tiene mucho de eso. [...] el Rodrigo es el gran articulador, el gran impulsor. Ese compadre es el que tenía grandes ideas. (Entrevista, 27 de julio de 2018)

Tras el golpe de Estado, Vera se había exiliado en Argentina, donde rápidamente se vinculó al Centro de Investigaciones Educativas y publicó algunos trabajos referidos al perfeccionamiento, las condiciones de empleo y el rol del sector docente, mientras también estudiaba en la Escuela de Psicología Social de Enrique Pichón Riviere.

Por su parte Ricardo Hevia Rivas ingresó al PIIE en 1972 como ayudante de investigación de Marcela Gajardo, quien había trabajado con Freire en educación rural de adultos. Luego pasó a ser ayudante en un proyecto dirigido por José Bengoa. Tras el golpe se fue a Stanford a hacer un doctorado, pero no finalizó su tesis, pues se quedó sin posibilidad de financiamiento cuando las autoridades impuestas en la UC le retiraron el patrocinio al PIIE en 1977. En esas mismas fechas, Vera volvió desde Argentina y se vinculó primeramente al Centro de Estudios Económicos y Sociales Vector, identificado con militantes socialistas. Allí Vera, junto a Iván Núñez y Eduardo Castro se hicieron parte de un pequeño taller de estudios educacionales (Nervi, 2013), mientras en la Academia de Humanismo Cristiano a fines de abril de 1979 se conformó el Círculo de Educación, donde también participó Núñez. Por su parte, Ricardo Hevia seguía en PIIE, donde en 1980 asumió como subdirector.

${ }^{5}$ En junio de 1970 por ejemplo, Vera publicó junto a Francisco Vergara, "Presentación de las obras de H. Marcuse", Cuadernos de la Realidad Nacional, (4), 179-195. También en el Centro de Estudios de la Realidad Nacional (CEREN) de la UC impartió durante 1970 junto a Rodrigo González un seminario titulado "El movimiento estudiantil” y en 1972 y 1973 el curso "Educación e ideología en Chile” junto a Guillermo Labarca. 
Fue así como en 1979 Vera, Hevia y Núñez constituyeron el núcleo de lo que sería $E l$ Pizarrón hasta 1990, al que luego se sumaría Eduardo Castro Silva, profesor socialista que había sido Decano de la Facultad de Educación de la Universidad Técnica del Estado durante la Unidad Popular y desde 1979 era propietario y director del colegio privado Kilpatrick, ubicado en el sector oriente de la capital. La experiencia política de estos intelectuales educadores se consolidó como grupo cuando a inicios de los ' 80 s estos cuatro integrantes de la revista se vincularon al PIIE, asumiendo Iván Núñez la dirección de este en 1981.

El Pizarrón contó además con un grupo de colaboradores, siendo la profesora feminista Gabriela Pischedda Larraín, también militante del MAPU y titulada en la UC, la más destacada y persistente. ${ }^{6}$ Además, existieron numerosos educadores que colaboraron escribiendo ocasionalmente en la revista, uno de ellos, de forma intermitente, fue Carlos Eugenio Beca, quien a fines de los '70s era el representante del MAPU-OC en las reuniones de articulación de las diversas tiendas políticas al interior del magisterio (Pavez, 2010). También durante un tiempo contribuyó con algunos artículos la profesora Aida Migone, que provenía desde el PC, pero de una línea más heterodoxa en términos educativos, articulada en torno a las ideas experimentales del Liceo Manuel de Salas. Durante estos años Migone era directora del colegio particular Francisco de Miranda, uno de los establecimientos alternativos identificados con la izquierda. Por eso existió una vinculación con Eduardo Castro, director en el colegio Kilpatrick.

El núcleo duro y los colaboradores conformaron un destacado grupo intelectual, con importantes redes en las organizaciones opositoras a la dictadura. El núcleo se reunía semanalmente todos los lunes, rotando entre las casas de los integrantes, donde debían ocuparse algunas medidas de seguridad, especialmente coartadas en caso de que fueran sorprendidos por fuerzas del régimen. Esa lógica de trabajo fue conformando una gran amistad, donde las familias también comenzaron a colaborar de múltiples formas con la revista, especialmente las esposas (Nervi, 2013). Ellas también fueron parte de esa red más amplia de la que formaba parte $E l$ Pizarrón. Carmen Garretón, esposa de Rodrigo Vera, trabajó durante toda la década del '80 en la Vicaría de la Solidaridad, mientras que Marta Zeballos, profesora y bibliotecaria, esposa de Iván Núñez, fue documentalista en la biblioteca del CIDE.

El carácter "no público" de la revista (en el sentido que no se daba a conocer una dirección a la que dirigirse), solo posibilitaba que llegaran colaboraciones de personas conocidas. Jorge Olivo recuerda: "En una ocasión publicaron una poesía mía "Plegaria de un profesor municipal" [n`13, abril de 1981]. Yo firmaba como "Olivillo", aunque lo publicaron como anónimo" (Entrevista, 27 de julio de 2018).

La dinámica de elaboración de la revista consistía en que todos los escritos eran discutidos en las reuniones, al igual que el diseño, pero por lo general existió una coincidencia política respecto a las diversas temáticas. $\mathrm{Ni}$ en la lectura de la revista ni en los testimonios de los protagonistas se aprecian divergencias importantes, aunque si desarrollos y cambios en los posicionamientos políticos. Nunca los artículos fueron firmados, por lo que, si bien existieron matices, no se aprecian posiciones contradictorias.

El grupo de colaboradores apoyaba en todo el proceso, ya sea aportando textos, ideas, debates, pero también en la distribución de la revista, siendo esto último lo más complicado en

\footnotetext{
${ }^{6} \mathrm{~A}$ inicios de los '80s fue parte del Grupo de Investigaciones Agrarias de la Academia de Humanismo Cristiano, encargada de las investigaciones sobre metodologías conducentes a la participación y organización de la mujer. Más tarde fue parte del Centro de Educación de Adultos para América Latina (CEAAL). A fines de esa década y durante la siguiente publicó varios trabajos sobre la Mujer.
} 
los primeros años. Con el avanzar de la década de los '80s la responsabilidad total del grupo editorial fue dividiéndose, pues en un inicio eran ellos mismos (y sus familiares) quienes imprimían las copias en mimeógrafo y se preocupaban de la distribución (hacer paquetes, enviar por correos o distribuir mano a mano). Esto también fue aparejado con el aumento del número copias por edición. Las redes de distribución fueron importantes, pero las condiciones dictatoriales y otros motivos, llevaron a que en ocasiones el grupo editor se quedará con numerosas copias de algún número. Lo anterior, da cuenta de que el grupo intelectual a cargo de la revista consideraba esta labor como una acción eminentemente política, militante, pues se diferenciaba de roles más estrictamente académicos que de forma simultánea desarrollaba todo el grupo.

Al consultarle a los integrantes qué referentes tenían en mente al construir El Pizarrón, aparece la revista Educación y Cultura (fundada en julio de 1984) de la Federación Colombiana de Educadores (FECODE), Cuadernos de Pedagogía de Barcelona (nacida en 1975) y la revista Tarea (fundada en Lima en 1980), todas articuladas en torno a la renovación pedagógica, con la especial diferencia que no se produjeron en contextos dictatoriales, por lo que tuvieron un carácter mucho más abierto, lo que favoreció la interacción con los lectores. La experiencia catalana de Cuadernos de Pedagogía fue asimilada en cuanto referente del movimiento de renovación pedagógico que se desarrolló durante la transición española. Mediante esa revista, se tomó conocimiento de las "escuelas de verano" que proliferaron durante esos años. El especial vínculo de El Pizarrón con Cuadernos de Pedagogía provenía de Alberto Silva, un amigo uruguayo que estuvo en Chile durante la UP, quien escribió en esa revista durante los '70s.

El integrante que mayores vínculos desarrolló con diversos sectores educativos y políticos de la oposición fue Iván Núñez, quien desde 1980 comenzó a publicar numerosos trabajos de historia de la educación, especialmente sobre la historia de las organizaciones docentes. Prueba de esto fueron sus publicaciones en otras revistas, como los Cuadernos de Educación, Convergencia o Signos. Jorge Pavez, un destacado dirigente de la CME recuerda que entre 19781979 Núñez "cumplía un activo rol de apoyo a las actividades de la Coordinadora, ya que frecuentemente se encontraba con nosotros en alguna charla de índole pedagógica" (2010, p. 85).

Si los vínculos de Núñez eran con diversos centros de estudios y con las organizaciones docentes, Vera y Hevia tuvieron una fuerte vinculación con las experiencias de Movimientos de Renovación Pedagógica, especialmente con el Grupo Espacio, formado en 1984, desde donde se realizaron diversas actividades y encuentros de discusión sobre prácticas pedagógicas transformadoras y horizontales que superasen el autoritarismo escolar. Hevia recuerda que "Espacio no estaba conectado directamente a El Pizarrón, pero eran colaterales nuestros. Compañeros de camino. Pero El Pizarrón era aparte" (Entrevista 12 de octubre de 2021).

De esta forma, El Pizarrón fue partícipe de una red intelectual pedagógica que se movió entre ámbitos políticos (Convergencia Socialista), de renovación pedagógica (Grupo Espacio), académicos (PIIE) y sindicales (la CME, AGECH y el CP). En ese sentido, la revista buscó ser un referente que articulara ese complejo intelectual pedagógico, donde sus autores no pretendieron ser colaboradores únicamente de la revista, sino aportar simultáneamente en diversos proyectos para expandir la zona de influencia. El rol específico de la revista era poder llegar a los profesores de base, que muchas veces no podían participar en otras instancias, por tiempo, temor, porque el lenguaje académico le resultaba alejado o porque las organizaciones docentes eran limitadas respecto a discusiones pedagógicas, pero que podían leer la revista en sus casas y reflexionar sobre las prácticas y las políticas educacionales, y ojalá comentarlas con otros docentes. 
La autodefinición que la revista se dio en septiembre-octubre de 1983, es precisa respecto del núcleo intelectual que hemos descrito:

un grupo de educadores que han convergido desde distintas experiencias socio-políticas y profesionales; dirigido a todos los interesados en democratizar la educación, en el contexto de la lucha del pueblo de Chile por liberarse y construir una democracia participativa y solidaria, cuya profundización tiene un nombre: socialismo. (El Pizarrón, $\mathrm{n}^{\circ} 25,1983$ )

El rol de los intelectuales integrantes de El Pizarrón fue variando en su autocomprensión, pasando de intentar contribuir a la construcción del socialismo a adquirir un carácter más neutro, de experto o tecnócrata. Sin embargo, se mantuvo durante parte importante del periodo su experiencia de tipo "basista" (Moyano y Lozoya, 2019), donde su militancia se desarrollaba junto a las organizaciones sociales, mediante la investigación-acción, especialmente en las coincidencias con los grupos de renovación pedagógica y con las organizaciones gremiales.

\section{La materialidad}

Como señalamos, El Pizarrón nació con un formato artesanal, motivado principalmente por las condiciones represivas. Se copiaba en mimeógrafo, en hojas de roneo tamaño carta, las que luego eran corcheteadas manualmente, con unas 4 páginas en un inicio y "unos pocos cientos de ejemplares" (El Pizarrón, $\mathrm{n}^{\circ}$ 40, 1986). Una vez que la dirección fue asumida por Vera y Hevia en 1979 se dio paso a una mejora en cuanto a su materialidad, manteniendo el tamaño, pero poco a poco se fue aumentando el número de páginas y la impresión pasó a un mimeógrafo de mejor calidad. Así en el número 9, de abril de 1980, alcanzó 38 páginas, pero manteniendo una calidad de impresión artesanal. En el número 12, de octubre de ese mismo año, la portada tuvo mucha mejor calidad, al igual que su diseño interno, alcanzando 86 páginas.

Sin embargo, en su número de abril de 1981, la portada volvió a aparecer en papel roneo y la cantidad de páginas bajó a 42, pero se mantuvo la calidad del diseño. Lo anterior da cuenta de la dificultad para alcanzar un financiamiento regular, el que sólo logró mayor consistencia en 1985, con una mejor portada, un mejor uso de imprenta, desapareciendo los corchetes, los que fueron reemplazados por un formato librillo encuadernado y el uso de papel blanco para el interior. Respecto de la cantidad de páginas, esta siempre varió, pero desde octubre de 1981 en adelante se estabilizó en una cantidad que osciló entre 56 a 64 páginas. Finalmente, hacia 1988 el último periodo de la revista fue mucho más profesional, donde recién se incluyó alguna dirección donde los lectores poder dirigirse.

Ricardo Hevia señala que el tema de la imprenta fue bastante complicado, por las condiciones dictatoriales. Durante un tiempo solo se pudo ocupar un mimeógrafo y una fotocopiadora que facilitaba la Facultad Latinoamericana de Ciencias Sociales (FLACSO), hasta que pudieron acceder a una imprenta. Más tarde habrían recibido apoyo de una entidad europea para financiar la revista, gastos destinados a papel, imprenta y distribución, pues la revista siempre fue gratuita (Entrevista 12 de octubre de 2021). Iván Núñez confirma esto señalando que ese financiamiento provino de agencias holandesas (Nervi, 2013). 
En el número 9, de abril de 1980, ya se aprecia el uso de una simbología o logo para la revista, compuesto por unas siluetas de niños tomados de las manos, el que en la edición número 12 ya apareció con su estética definitiva: la silueta de dos niños de la mano encerrados en un círculo, los que, en palabras de Vera, representaban la centralidad que debían tener los niños en los procesos de aprendizajes y la idea de ir tomados de la mano buscaba destacar una escuela solidaria y democrática (Entrevista, 27 de septiembre de 2021). Quien habría creado dicho logo fue Gabriela Pischedda.

En las portadas por lo general se usó un diseño simple, que no incluía texto sino una o varias imágenes, siempre con el logo de El Pizarrón. Desde 1985 comienzan a aparecer portadas con fotografías y desde 1987 incluyen diversos colores. En un inicio, el interior de la revista no había grandes ornamentaciones, ni líneas verticales de separación (corondeles); cuando se usaron estas fueron bastante artesanales, incluyendo cuadros con frases, las que mecanografiadas lograban una calidad muy modesta. Con el correr de los números fueron apareciendo más dibujos y ornamentaciones que acompañaban los artículos, pero hacia el final de la década, los últimos números fueron mucho más formales y faltos de imágenes. Salvo en algunas ediciones, por lo general la revista evitó los textos largos y el predominio de la linealidad con grandes masas textuales. Siempre se buscó el juego de espacios blancos y textos, permitiendo una lectura más amena, lúdica, y entregando opciones para el descanso de la lectura, lo que era coherente con la búsqueda de una pedagogía innovadora, experimental, por lo que no podía ser solo texto tradicional, sino que debía apuntar a escritos cortos y provocativos. Solo en artículos muy puntuales se ocuparon citas a pie de página.

Paulatinamente se fue introduciendo mayor cantidad de dibujos, los que a veces tenían relación con el texto y otras no, pero desde 1985 se aprecia que los dibujos son creados específicamente para cada artículo, representando una forma más dinámica de comunicar lo que en el texto se señala. Desde 1987 aparecen fotografías en el interior de la revista.

La revista habría alcanzado alrededor de 57 números hacia marzo de 1990, teniendo su periodo de mayor difusión y alcance entre 1982 y 1987, etapa en que publicó 5 números cada año entre los meses escolares: marzo-diciembre.

El alcance de El Pizarrón estuvo principalmente en el magisterio activista, opositor a la dictadura. Debido a que la revista tenía su origen en la ciudad de Santiago, esta tuvo un alcance principalmente en la región Metropolitana. Sin embargo, con el correr del tiempo también comenzó a llegar a regiones, donde se enviaba por encomienda a contactos conocidos. Lamentablemente, la no existencia regular de "cartas de lectores" impide apreciar quiénes leían la revista. No obstante, en algunos números de 1980-1983 aparecieron contribuciones enviadas por lectores cercanos, especialmente referidas a la recepción que tenía la revista, la que durante esos años tenía acogida principalmente en el profesorado del sector oriente de la capital. Sin embargo, en nuestra búsqueda hemos encontrado docentes de ciudades mucho más pequeñas, como Lota en la región del Biobío, que aún poseen copias de El Pizarrón. José Letelier, profesor de esa zona, opositor a la dictadura, pero no activista, recuerda que él pudo acceder a un número de la revista pues en 1986 el comunal democratizado del Colegio de Profesores hizo llegar algunos números a los establecimientos, y quedaron algunas en la sala de profesores de su escuela desde dónde él tomó una y la guardó (Entrevista a José Letelier, 28 de junio de 2017). El hecho de poseer solo un número de la revista da cuenta que el alcance de esta era intermitente, y los profesores podían acceder a ella "cuando le llegaba".

Hevia recuerda que en ocasiones la revista llegaba a directores de colegios o profesores que no la recibían de buena forma, por su contenido antiautoritario en lo pedagógico o por sus 
posicionamientos políticos. Esto de inmediato representaba el peligro de que se informara a la policía. El mismo Hevia señala: "en una ocasión, en un colegio donde hacía clases la señora de Federeci, rector designado de la Universidad de Chile en 1987, sorprendieron a una profesora con una revista y la amenazaron con denunciarla a ese personaje. La profesora terminó muy asustada y era amiga nuestra" (Entrevista 12 de octubre de 2021). Inclusive, sectores políticos que se distanciaban de los posicionamientos de la revista también ayudaron en su distribución. Guillermo Scherping, profesor comunista y dirigente de la AGECH recuerda que:

Iván [Núñez] nos criticaba despiadadamente desde la revista El Pizarrón, revista que queríamos harto, porque nos servía mucho para el trabajo sindical. Nosotros desde la AGECH nos costaba sacar publicaciones, entonces El Pizarrón nos servía para llegar con algo a los profes, aunque no estuviéramos de acuerdo con todo lo que decía. (Entrevista, 25 de enero 2016)

\section{La estructuración de la revista}

Desde 1979, El Pizarrón adoptó una estructura basada en secciones, algunas de las cuales permanecieron hasta el cierre de la revista y otras fueron más ocasionales. Estas secciones por lo general tenían un responsable, lo que no quitaba que las propuestas debían discutirse en las reuniones de Comité Editorial. Así, por ejemplo, Rodrigo Vera tenía a su cargo la sección "Analicemos políticamente los problemas educativos" y "Sexión"; Iván Núñez estaba a cargo de "Algo de historia"; en temáticas de perfeccionamiento y descentralización escribían principalmente Vera y Hevia; y sobre políticas educativas escribían Vera y Eduardo Castro. Este último por lo general se enfocaba en cuestionar los intereses mercantiles que predominaban en la educación privada o la metodología Waldorf, tomando en cuenta su experiencia como director de un colegio privado alternativo. De esta forma, en el número 13, de abril de 1981, se especificaron cuáles eran los objetivos de la revista, aclarando en primer lugar que es un "material de discusión" y no busca entregar verdades definitivas, en una perspectiva, claro está, muy freiriana. Esas discusiones se orientaban hacia problemas que atañen al profesorado, referidos a cuatro ámbitos: su situación laboral, su práctica en el aula, la política educacional vigente y los problemas sociales y políticos en los que se inserta la escuela.

Uno de los temas que más duramente fue atacado desde la revista fue la privatización de la educación, no desde una posición que intentara negar la participación de privados, sino apuntando principalmente a la educación técnica postsecundaria (Institutos Profesionales y Centros de Formación Técnica) y a las redes de colegios privados que estaban lucrando con la política educativa del régimen. Ricardo Hevia recuerda:

una vez escribimos algo donde se criticaba a Filomena Narváez, dueña de una red de colegios. Denunciábamos cómo un privado podía enriquecerse. Eso le causó una indignación tan grande que llamó al PIIE, y ahí se lavaron las manos, no nos vincularon con la revista. Pero, eso nos indicó que estábamos realmente llegando donde queríamos. Denunciábamos la política de la dictadura y llegábamos al interior de las escuelas. (Entrevista 12 de octubre de 2021) 
En cambio, desde El Pizarrón tuvieron una mirada más benigna respecto a los establecimientos privados, aquellos que no recibían subvención del Estado. Sobre estos se destacaron las condiciones en que impartían la enseñanza, número de estudiantes, infraestructura, material de apoyo, etc., al igual que los salarios que pagaban a los docentes, la estabilidad de estos, la amplitud de programas y el reconocimiento del papel de los sindicatos, lo que permitía la obtención de beneficios, pero también el perfeccionamiento docente con cargo al establecimiento (El Pizarrón, $\mathrm{n}^{\circ}$ 53, 1989). La visión ideal que se tenía provenía sin duda de la cercanía de los integrantes del grupo con proyectos privados innovadores, pero que no correspondía al conjunto de los establecimientos particulares, varios de los cuales tensionaron sus relaciones cuando las organizaciones sindicales exigieron reivindicaciones a fines de los ' 80 s y en la década siguiente.

Las temáticas de la revista giraron principalmente sobre políticas educativas, informaciones y discusiones gremiales, trabajo docente, dinámicas pedagógicas para potenciar los temas políticos en las escuelas, y también reflexiones políticas de contingencia. En ese sentido, las temáticas de El Pizarrón son representativas de los debates más profundos que se dieron durante la década de 1980 respecto a políticas educativas.

Rodrigo Vera recuerda que en esa época ya existía en integrantes del grupo una importante recepción de las ideas de Foucault, especialmente de la "micropolítica", las que aplicaban al espacio escolar, como un espacio de disputa de poder (Entrevista, 27 de septiembre de 2021). Lo anterior fue reforzado con la importante influencia gramsciana que se percibe directamente al leer la revista, al buscar "crear una cultura popular capaz de ahogar la ideología omnipresente de la clase dirigente" (El Pizarrón, $\mathrm{n}^{\circ}$ 12, 1980). Por eso se adscribía y difundían las ideas del Movimiento de Renovación Pedagógica, como el cambio de la escuela tradicional por una democrática y cívica, donde la pedagogía fuese un ejercicio eminentemente transformador.

Esas ideas de renovación pedagógica debían articularse mediante las organizaciones docentes, pero considerando que el centro del poder estaba en el profesor de aula, pues la lucha en la escuela era fundamental. Lo anterior se materializaba en la columna, bajo responsabilidad de Vera, "Hagamos política en la escuela", la que planteaba reflexiones y experiencias que contribuyeran a buscar intersticios de generación de poder, para que estudiantes y comunidades hicieran política y no sean considerados receptores pasivos.

La "editorial" representaba el espacio de posicionamiento político más firme y decidido, donde se buscaba tensionar al profesorado frente a la coyuntura política y educativa impuesta por la dictadura. Esta sección era la que debía contar con el mayor consenso entre los integrantes, pues en el resto de las columnas, al ser anónimas, podían no ser compartida de forma absoluta por alguno de los integrantes, quienes, en otra columna, en ese o en otro número, podían plantear posiciones distintas. De todas formas, las discrepancias nunca fueron insalvables, sino más bien lo que existía era una diferencia de enfoques. Si Iván Núñez se centraba más en las estructuras, leyes, etc. Rodrigo Vera, fiel representante pedagógico mapucista, tenía una mirada más freiriana, centrada en los agentes educativos y crítica del autoritarismo. En ese sentido, consideramos que la revista conformó una comunidad intelectual fuerte, donde el anonimato de los textos le daba a El Pizarrón un sentido de cuerpo.

La revista también acogió recomendaciones culturales, comentarios de libros, películas, obras de teatro, etc. Además, comúnmente se publicaron fragmentos de textos de autores destacados como Dewey, Freire, Freinet, Sartre, Ilich, Cousinet o artículos sobre Piaget, Giroux, etc. Además, se publicaron poemas y cuentos cortos de Mistral, Neruda, Benedetti y Cortázar. En 
ocasiones se reprodujeron notas de otras revistas de oposición, como Análisis, Cauce o La Bicicleta. Pero nunca se incluyó avisaje ni publicidad.

Dos secciones son interesantes de destacar. "Algo de historia", una de las de mayor duración en la revista, nos permite apreciar la perspectiva instalada por Iván Núñez respecto a la historia de la educación, la que es coherente con su obra personal, pero que acá se dirigía directamente hacia lectores docentes. La mayoría de estos artículos estuvieron enfocados en rescatar las experiencias del proyecto educacional de los años '20s, los proyectos experimentales, las Escuelas Consolidadas, y el proceso de descentralización y unificación del gobierno de Allende. Así, esta sección buscó destacar una cierta tradición participativa y descentralizada en la educación chilena, dividiendo aguas con el grueso del profesorado chileno, oficialista u opositor, que defendía una tradición educativa Estadocéntrica. Algunos de sus títulos fueron: "Los trabajadores, el magisterio y los orígenes de la Constitución de 1925 " $\left(\mathrm{n}^{\circ} 12,1980\right)$ "Sindicalismo docente y legalidad" ( $\left.\mathrm{n}^{\circ} 13\right)$; "Cincuenta años de experimentación educacional en Chile" (n॰ 17, 1982); "Magisterio chileno: historia y perspectivas" (n॰18, 1982); "La educación durante el segundo gobierno de Ibáñez" (n³5, 1985); "Transcripción: "Informe sobre Escuela Nacional Unificada (1973)" (n 42, 1986); "Maestros, el Pueblo confía en ustedes...". Discurso de Salvador Allende. Año escolar 1971” ( $\left.n^{\circ} 44,1987\right)$; “Hubo Descentralización antes de Pinochet?" (n 53, 1989).

Por otro lado, "Sexión" no solo representó un creativo juego de palabras, sino también una particularidad propia de la revista, como fue poner en discusión los roles de género, especialmente al interior de la escuela, y la participación de la mujer en las actividades y decisiones gremiales. En esto se jugaba el rol reproductor y transformador de la escuela. Fue así como se publicaron entrevistas a profesoras feministas y se analizó el sentido real de la coeducación, la cual por lo general era entendida como sinónimo de escuelas mixtas, pero no se apuntaba a integrar los sexos de la manera más plena posible en temas curriculares como responsabilidades y trato. Frente a esto se presentaba, lo que era algo característico de la revista, una guía para la acción coeducativa del profesor y una propuesta de Taller para ser realizada por un colectivo de profesores.

El trabajo hermenéutico sobre los contenidos de la revista nos permite destacar sus posicionamientos críticos respecto a las políticas educativas implementadas durante la dictadura, pero al mismo tiempo una búsqueda de distanciamiento de los posicionamientos tradicionales de la izquierda sobre educación. En ese sentido, el grupo intelectual de El Pizarrón buscó disputar los sentidos al interior del campo educativo que permitiesen el establecimiento de determinadas políticas educativas en el futuro democrático al que gradualmente avanzaba el país.

\section{Hacia la Convergencia Socialista}

El mencionado núcleo de intelectuales que sostenía la revista tempranamente se fue identificando con el movimiento Convergencia Socialista donde se agruparon diversos sectores del socialismo. Esta identificación, salvo en el caso de Eduardo Castro, se efectuó más bien de forma directa con ese movimiento y no desde sus partidos de origen. MAPU,

Vera aclara que él se integra a Convergencia Socialista en 1979 siendo miembro del 
Entonces El Pizarrón asume la línea política de la Convergencia Socialista, donde nos juntamos militantes MAPUs, socialistas y muchos ex militantes, quienes siendo profesores queríamos ser parte de la oposición. Una disidencia donde tú ibas a enfrentar a la dictadura, pero no vinculado a la lucha armada, pues esta impedía hacer política y generar redes. Te obligaba a montar una estructura clandestina, la que tendía a aislarte. (Entrevista, 27 de septiembre de 2021)

De esta forma, en 1979 El Pizarrón tuvo una reorientación, manteniéndose como una revista clandestina, sin autorización pública para su funcionamiento, ni figuración de lugar de edición ni autores de los escritos, pero buscando contribuir a la oposición a la dictadura desde una mirada más abierta, de masas, la que se consideraba antagónica a la lucha armada. Con esto, se enfrentó a otras fuerzas políticas que precisamente en esos años llevaron a cabo un proceso de radicalización, como el Partido Comunista, el que en 1980 inició su Política de Rebelión Popular de Masas, la que contempló todas las formas de lucha, incluso la lucha armada. Estas tensiones no fueron ajenas al interior del MAPU, pues si bien el sector de los militantes más experimentados se fue acercando a la Convergencia Socialista, un sector importante de la juventud fue recepcionando las tesis de la lucha armada, provocando un fraccionamiento en 1982, el que dio vida al MAPU-Lautaro. Rodrigo Vera hace explícito este punto, "nosotros comenzamos a definirnos claramente contra la lucha armada" (Entrevista, 27 de septiembre de 2021), lo que es reafirmado por Núñez:

Cuando aparecieron las protestas [...] tomamos distancia. [...] salir a la calle comenzó a convertirse en una operación de violencia que, más que de masas, era de grupos de disciplina y carácter militar. Cuando comenzaron a aparecer los rodriguistas, tuvimos discrepancias respecto a esas estrategias y expresiones tácticas, con esas condiciones políticas y sus efectos en los jóvenes y estudiantes de las escuelas. Hubo tomas de liceos y periódicos clandestinos que se vanagloriaban de las tomas, hablando en un lenguaje militar [...]. En el fondo, nosotros tratábamos de mantener un cierto respeto a la peculiaridad del mundo educacional, que no fuera instrumentalizado dentro de estas estrategias de la lucha armada. (Nervi, 2013, p. 120)

En línea con lo anterior, es que consideramos que existió un segundo periodo de $E l$ Pizarrón entre 1979 y 1984, donde el proceso de renovación socialista estaba en curso, pero que aún se apostaba a una unidad de la izquierda. Lo anterior habría permitido que educadoras identificadas con el PC como Aída Migone colaborara con la revista en este periodo. De esta forma uno puede entender que en abril de 1980 se planteara "la unidad de la izquierda y la convergencia de todas las fuerzas que están por un socialismo revolucionario y democrático enraizado en nuestra realidad", mientras que en lo pedagógico se hable del "modelo educativo burgués" (El Pizarrón, $\mathrm{n}^{\circ}$ 9, 1980). Como si fuera poco, en ese mismo número una columna titulada "Por la democratización total", planteó la "conformación de un movimiento mayoritario en lucha frontal contra la dictadura, decidido a derrocarla y gobernar el país", mediante "un compromiso que ponga hoy en el centro la lucha de masas y de ir impulsando todas las formas de lucha hacia un levantamiento nacional y popular contra la tiranía", para instalar "un gobierno popular, democrático y revolucionario". La influencia de la táctica del PC acá era evidente.

De esta forma, en 1980 las ideas de autores de inspiración marxista seguían siendo una de las teorías contemporáneas posibles para una escuela diferente, destacándose su análisis de la 
escuela en su significación social y política (El Pizarrón, $\mathrm{n}^{\circ}$ 12, 1980). Lo anterior fue reforzado en ediciones siguientes con un contrapunto entre las miradas sobre educación y trabajo de dos educadores soviéticos: A.S. Makarenko y P.P. Blonskij (El Pizarrón, $\mathrm{n}^{\circ}$ 18, 1982).

El tono maximalista expresado anteriormente da cuenta de que al menos a inicios de la década las posiciones rupturistas, aún podía tener alguna acogida en la revista. Sin embargo, el componente ideológico que más se destacaba era la idea de un "socialismo democrático enraizado en nuestra realidad", lo que fue reforzado en el número 10, de junio de 1980, donde se expresaba que El Pizarrón "quiere ser expresión de todos aquellos que luchan por la unidad de la izquierda en la construcción de una democracia socialista". En esa misma edición, apareció un artículo titulado "Seis tesis sobre Convergencia Socialista", donde frente a la crisis de la izquierda se apelaba a un reordenamiento en curso del cuadro partidario de la izquierda, el que debía rechazar todo dogmatismo, especialmente la "esterilización stalinista del marxismo", e incorporar los aportes del pensamiento cristiano en cuanto mensaje de liberación humana y de motivación ético moral para el fortalecimiento de la lucha revolucionaria. Lo anterior, se habría desvirtuado en la década del '60 cuando el PS dejó de dar cabida a las fuerzas latinoamericanistas y propias del pueblo chileno, al adoptar el leninismo como eje de su cosmovisión. Ahora se buscaba que "democracia y socialismo se contengan mutuamente". Este rescate por los aspectos endógenos de la ideología socialista (Santoni, 2013), se sustentaba en el supuesto de que las "condiciones nacionales" eran completamente exóticas respecto a aspectos estructurales de la lucha de clases.

Así, en su edición de septiembre-octubre de 1983, se señaló:

Nuestra apuesta por la democracia socialista, por una utopía libertaria y fraterna, no se agota en la lucha por el poder político, como tradicionalmente lo han entendido los partidos de izquierda, ni en la lucha por pequeñas cuotas de poder en organizaciones sociales o instituciones. Luchamos por desarrollar la cultura del socialismo, aquí y ahora, por construir nuevas relaciones sociales en el ámbito de lo cotidiano, con o sin poder político. De aquí nuestro rechazo al autoritarismo en la macro-sociedad, pero también en la escuela y el aula, en el sindicato y el partido, en la familia y en la pareja; y nuestra demanda de relaciones igualitarias, solidarias y posibilitadoras del crecimiento individual-grupal. (El Pizarrón, n ${ }^{\circ}$ 25, 1983)

Como vemos, la consideración del socialismo con un carácter esencialmente democrático y participativo era un sello distintivo, que los distanciaba de las experiencias socialistas de corte leninista. Esto en términos educacionales, era bastante importante, pero que se continuaría acrecentando hacia fines la década, dejando de hablar de socialismo en cualquiera de sus formas.

El distanciamiento más claro de los países socialistas del Este se produjo a raíz del golpe militar polaco que disolvió Solidarność, encarceló a su principal líder Lech Walesa y proscribió a las organizaciones sindicales y sociales. El Pizarrón se hizo eco de la condena a estos sucesos por parte de Convergencia Socialista, y tradujo y publicó en su número 17 un documento del Partido Comunista Italiano que iba en una línea similar a la conjunción de socialismo y democracia que se venía esbozando. También se reprodujo una resolución de la Confederación Mundial de Organizaciones Profesionales de la Enseñanza (CMOPE), no alineada políticamente, sobre los sucesos de Polonia donde saludaban la lucha por la autonomía y la independencia sindical. Esta crítica al socialismo de Estado era paralela a la renovación pedagógica. Se buscaba un modelo de 
socialismo no autoritario, al igual que se pretendía generar prácticas pedagógicas más horizontales.

El sostenimiento de la idea de "socialismo", operó mediante un relevamiento de figuras históricas del Partido Socialista, como los educadores Jorge Peña Hen y Eugenio González, de quienes se rescataba su imagen de socialistas cultos y académicos, alejados de perspectivas rupturistas. Este revisionismo histórico alcanzó sus tonos más extremos en la revaloración renovada de la política educativa del gobierno de Allende, en la cual Iván Núñez había tenido importantes responsabilidades, la que comenzó a ser considerada como culminación de un proceso de democratización educacional gestado desde los gobiernos precedentes, con los que habría una relación de continuidad, casi sin existencia de aspectos innovadores respecto a las políticas de los gobiernos previos. ${ }^{7}$

Este socialismo "releído y reforzado" presentaba cinco características centradas en: el respeto a los derechos humanos; la revaloración de la democracia; el representar una respuesta a toda una nación y no solo a una clase; estar apoyado en movimientos sociales autónomos; y propiciar una organización autogestionaria y descentralizada de la propiedad y el poder.

En el número 16 de la revista, de diciembre de 1981, se publicó un documento de Convergencia Socialista llamado "Un horizonte democrático para Chile", donde se apuntaba directamente a la necesidad de una renovación política y de revaluar la experiencia de la Unidad Popular. También se criticaron los socialismos reales, insistiendo en los métodos democráticos y dividiendo aguas con el PC, y también con el almeydismo. ${ }^{8}$ Este documento reconoce insertarse en el proceso global de renovación ideológica que se desarrollaba en diversos países, pero sin la búsqueda de la conformación de un nuevo bloque que tenga a un país específico como centro.

Desde fines de 1985 en adelante, desaparecen los debates en torno al carácter del socialismo deseado. Más bien las disputas desde la renovación socialista se trasladan a las pugnas gremiales, la estructura de la organización docente y las políticas educacionales. En las primeras elecciones internas del Colegio de Profesores, en diciembre de 1985, El Pizarrón tomó partido por la lista comandada por candidatos militantes de la DC y el PS-Núñez. Con esto ya cabe una interrogante respecto a sus anteriores críticas a la falta de independencia partidaria de las entidades gremiales, las que al parecer eran nocivas si estas se identificaban con organizaciones marxistas, en un posicionamiento similar al del "sindicalismo libre" norteamericano. Varios de los candidatos de esa lista eran completamente desconocidos en las bases docentes, designados ahí más bien por las "cúpulas partidarias". Lo anterior no quitó que esa lista lograse las mayores preferencias, gracias a la alta votación de los candidatos democratacristianos, lo que permitió el arrastre de candidatos con minoritarias adhesiones, como los del socialismo renovado, muy por debajo de otras fuerzas de izquierda como los comunistas o almeydistas.

Previo a esa primera elección, El Pizarrón declaró también su apoyó al Acuerdo Nacional para la Transición a la Plena Democracia iniciativa propiciaba por el cardenal Fresno y que fue firmado por 11 partidos políticos en un abanico que fue desde la derecha moderada hasta el socialismo renovado. La revista apoyó esa iniciativa por considerar que representaba los "caminos civilizados", en una nomenclatura con reminiscencias sarmientinas donde los restantes caminos, como los rupturistas, serían los propios de la barbarie. Aquellas posiciones

${ }^{7}$ Esta mirada fue desarrollada de forma más profunda en el libro de I, Núñez, Reformas institucionales e identidad de los docentes. Chile, 1960-1973 (1990).

${ }^{8}$ Sector mayoritario del fragmentado PS al interior del país, liderado por Clodomiro Almeyda y que sostuvo posiciones leninistas y cercanas a los países del Este hasta fines de la década de los '80s. 
maximalistas, se decía en septiembre de 1985, representaban una "conducta política que pretende obtener de inmediato, en corto plazo y en todos y cada escenario, todos los objetivos de un sujeto histórico, sin importar las correlaciones de fuerza o las condiciones que los hagan factible [...] ignora que la política es el arte de lo posible" (El Pizarrón, $\left.\mathrm{n}^{\circ} 35,1985\right)$. El maximalismo, a juicio de la revista representaba "el peor favor que se le puede hacer a la causa de la democracia y de la justicia social". Esta mirada excluía los métodos violentos de los repertorios de acción política, poniendo en un mismo nivel la violencia del Estado dictatorial, y sus aparatos represivos, con las de las organizaciones populares que se rebelaban contra él. Esa vía, la insurreccional, sería un callejón sin salida, un camino de "la ya agotada mecánica de las "protestas", visión que a esas alturas era hegemónica en diversos intelectuales de origen mapucista, desde José Joaquín Bruner a Tomás Moulián, pasando por Eugenio Tironi de quien la revista reprodujo una de sus columnas en mayo de 1987.

Pasando de las críticas a las proposiciones, El Pizarrón volvía a definirse "por un socialismo integral, levantado en democracia y con respeto a los más altos valores de la Humanidad", donde las protestas y las acciones armadas no tenían cabida, pues la dictadura sería puesta en jaque por "una movilización social pacífica, pero activa". Finalmente, la revista en septiembre de 1985 estimaba que

el magisterio se sumará activa y responsablemente [...] el estilo civilizado de salida a la crisis nacional que propone el Acuerdo, es el propio de los educadores. Los educadores, por inserción social y por definición profesional, están comprometidos con los modos racionales y pacíficos de resolver los conflictos. Su vocación implica aceptación del pluralismo, el respeto al otro, la paz. (El Pizarrón, $\mathrm{n}^{\circ} 35,1985$ )

En las segundas elecciones del CP, cuando los dirigentes de la AGECH llevaron una lista, adelantando la autodisolución de esta, las críticas de El Pizarrón volvieron a aparecer. Pero a esas alturas, mediados de 1987, el proceso de renovación continuaba avanzando, cada vez más hacia posiciones de centro. Desde diciembre de 1986, Hevia, Núñez y Vera eran parte del Consejo de redacción de la revista Convergencia, en torno a la cual se fraguó el proceso de renovación partidaria. Por lo anterior, ya se evitaba de hablar de "categorías estrechas" como "izquierda" o "centro", las que serían caricaturas políticas, al igual que "más movilización" o "menos movilización", "puntudos" o "moderados", tal como se señalaba en la editorial de mayo-junio de 1987. En esa fecha, la revista dio a conocer que volverían a apoyar a:

la lista que en lo nacional exprese, a nuestro juicio, una estrategia de unidad más amplia de la oposición. Se trata de vencer la tendencia a excluir por razones doctrinarias y de vencer la tendencia a una hegemonía de clase, que hoy día es imposible y no conduce a lograr la vasta concertación social que se requiere para vencer a la dictadura. (El Pizarrón, $\mathrm{n}^{\circ} 44,1987$ )

Por eso optaban nuevamente por la lista que agrupaba a los candidatos de la DC, PR, Social Democracia y PS-Núñez. Este bloque sería el que habría comprendido que solo en torno al Colegio de Profesores se podría articular la unidad del magisterio y desde ahí era posible la movilización. "No queremos dar paso al "maximalismo", a aquel que pide toda la democracia, que exige movilizaciones que nadie puede lograr, que quiere involucrar al Colegio en una posición de vanguardia que no haría sino aislarlo" (El Pizarrón, n 44, 1987). Sin embargo, estas 
motivaciones no solo serían políticas y gremiales, sino también pedagógicas, pues dicha lista apuntaría a una alternativa educacional que

ya no defienden un añejo Estado Docente, como ideología del pasado hoy recurrente en muchos, sin que proyecten hacia el futuro una presencia estatal no burocrática ni centralizadora en la educación, combinada con formas participativas y comunitarias de propiedad y de administración de las unidades educativas y del sistema escolar. (El Pizarrón, $\mathrm{n}^{\circ} 44,1987$ )

Finalmente, señalaban que "estaremos con quienes promuevan un magisterio a la vez responsable y autónomo, en su práctica docente, en su práctica gremial y en su práctica política”, tras lo cual nombraban a los 3 candidatos del PS-Núñez de la mencionada lista como las alternativas más cercanas a sus planteamientos. Ninguno de ellos resultaría electo, a diferencia de los 6 democratacristianos, 1 radical, 2 comunistas, 1 socialista-almeyda, y 5 oficialistas. Al parecer, las ideas pregonadas por El Pizarrón no eran tan representativas del magisterio socialista, aunque a esas alturas gran parte de sus posicionamientos sí eran coincidentes con los del magisterio DC.

Curiosamente, fue en las elecciones de 1989 donde desde El Pizarrón fueron menos duros con las críticas a la lista de izquierda y menos grandilocuentes con la lista de la Concertación. En cambio, se criticó de forma general la inexistencia de debate en torno a la calidad de la educación durante la campaña. De todas formas, el análisis realizado en esta ocasión llevó a considerar que el alto apoyo recibido por Osvaldo Verdugo representaba la confianza del profesorado en la Concertación, lo que podía ser proyectable en las elecciones presidenciales de diciembre de ese año, con lo cual nuevamente no se apeló a la pretendida separación entre gremio y partido con la que enjuiciaban a la izquierda tradicional.

\section{Por una organización docente renovada}

La revista siempre mostró una particular atención hacia las organizaciones del magisterio, pues se entendía que gran parte de los objetivos perseguidos debían tener frutos colectivos y no solamente individuales. En esa línea constantemente se buscó que la renovación pedagógica fuera asumida por las organizaciones, aunque se sabía que esa tarea no era fácil, pues estás tenían una tendencia histórica a concentrarse en aspectos laborales y económicos.

Desde sus inicios se respaldó la conformación de la Coordinadora Metropolitana de Educadores (CME), impulsando el crecimiento de esta a partir de organismos de base en las escuelas y no por una búsqueda de grandes "superestructuras" políticas como había sido el SUTE. También se criticó la burocracia de la mayoría de las organizaciones en la historia. Se debe recordar que sobre este tema El Pizarrón contaba con la figura de Iván Núñez, pionero en los estudios sobre organizaciones docentes en Chile.

La revista se la jugó porque las organizaciones docentes levantasen un proyecto educativo, por eso desde la historia se rescataba la experiencia del magisterio en la década del '20. Al respecto se señaló que democratizar la educación "debe ser la preocupación central de nuestros gremios", es decir "democratizar las formas de trabajo cotidianas" (El Pizarrón, n 40, 1986). Guillermo Scherping recuerda: 
Yo creo que El Pizarrón tenía razón en ese aspecto. Nosotros en la AGECH no teníamos desarrollo de política pedagógica y educativa [...] no era nuestra fortaleza. Pero también políticamente estábamos convencidos que no era la necesidad principal en ese minuto, sino más bien defender a los profes del drama que estaban viviendo, estaban siendo despedidos, había mucha arbitrariedad, los detenían, muchas denuncias [...] la AGECH no podía ser en ese momento un Instituto de estudios o una academia. (Entrevista, 25 de enero 2016)

De todas formas, las necesidades del contexto dictatorial señalado por Scherping no fueron ajenas para la revista. Esta misma denunció le exoneración de dirigentes, despidos de profesores de base o la persecución a docentes militantes de izquierda. Inclusive, difundió también luchas magisteriales latinoamericanas, como la del SUTEP peruano o ANDES de El Salvador.

Los diversos periodos de la revista y sus posicionamientos políticos también se aprecian en sus análisis sobre las organizaciones docentes. Así entre 1979 y 1984 son constantes las críticas al Colegio de Profesores, por su posición obsecuente con la dictadura (sus dirigentes eran designados por esta). Por el contrario, se le dio bastante apoyo a la CME, pero criticando los posicionamientos cupulares verticalistas asociados a los partidos políticos de izquierda, los que eran mayoritarios en esa Coordinadora y también luego en la AGECH. El Pizarrón planteó una relación complementaria entre sindicatos y partidos, pero manteniendo su especificidad y rechazando la superposición del partido por sobre los sindicatos.

En el número 12, de octubre de 1980, se planteó que la recomposición de un sindicalismo docente renovado debía buscar la unidad nacional de los trabajadores de la educación, democracia y autonomía sindical, lucha por una educación democrática y por mejores condiciones laborales, búsqueda de solución a todas las necesidades y problemas de los trabajadores de la educación y sentido latinoamericanista. Todo lo anterior debía ir dentro de una lucha antidictatorial no clandestina, sino de cara a los educadores, con plena trasparencia. Por lo anterior, no fue extraño que en la revista también se diera cabida a una pugna surgida al interior de la CME, donde el zonal oriente de esa coordinadora, con el cual El Pizarrón tenía sus mayores vínculos, acusó a la conducción metropolitana de la entidad de prepotencia política y sectarismo por no haber respetado la decisión de las bases de esa zona de abstenerse de participar en el plebiscito efectuado por Pinochet en 1980, frente al que la CME decidió llamar a votar No. ${ }^{9}$

Entre 1980 y 1981, la revista fue clara en señalar que la necesidad organizativa de los profesores era un sindicato y no un colegio profesional, pero este posicionamiento también fue variando durante la década. Por esto, en abril de 1981, dentro de las posibilidades existentes se propuso construir asociaciones gremiales alternativas al $\mathrm{CP}$, cuestión que unos pocos meses después se llevó a cabo desde la CME y otras organizaciones regionales, las que dieron vida a la AGECH, aunque desde la revista se adelantó que ese camino era estrecho, limitado a la vanguardia del magisterio, lo que era sinónimo de sectarismo o voluntarismo.

\footnotetext{
${ }^{9}$ Más tarde, ese zonal continuó trabajando como DECAL Oriente, desde donde tuvieron resistencias para disolverse y sumarse a la AGECH, pues optaban por un movimiento pedagógico en vez de un sindicato. Este sector convocó a un Encuentro de Innovadores en Educación en diciembre de 1981 y luego continuaron editando el boletín $L a$ Tarea. En 1984 conformaron el Grupo Espacio, una experiencia de renovación pedagógica, donde participaron Rodrigo Vera y Ricardo Hevia. Otra experiencia similar a esta fue la del Grupo Freinet, el que funcionó desde 1986.
} 
Con la AGECH se tuvo un respaldo crítico hasta 1984, lo que daba cuenta de que, si bien El Pizarrón se hizo parte decidida de la renovación socialista, no fue mecánica su adhesión a la estructura partidaria en que se articuló ese proceso, como fue el PS-Núñez, con el que solo se empezó a identificar desde 1985. Decimos esto porque el profesorado de este partido no participó en la AGECH, siempre apuntó a "rescatar" el Colegio de Profesores. Estos matices dan cuenta de que la llamada renovación socialista experimentó en su interior diversas temporalidades (Matamoros, 2019).

Ricardo Hevia recuerda que en determinado momento la revista discutió si fortalecer la AGECH o disputar el CP. La cantidad de bienes inmuebles y de capital, transferidos por la dictadura al CP desde la expropiación a las antiguas organizaciones prescritas, fue un factor importante en inclinar la balanza hacia el Colegio, "pero el interés de El Pizarrón era que el gremio se preocupara también del contenido pedagógico de la acción docente. Queríamos darle ese sentido, que ayudara a la democratización" (Entrevista 12 de octubre de 2021). Además, la alta afiliación al CP tan fue una variable determinante. En ese debate fue muy importante el rol jugado por la CMOPE. Esta organización internacional apoyó bastante a la AGECH en la denuncia de las violaciones a los derechos humanos sufridas por el magisterio. Pero su característica específica era que agrupaba a entidades profesionales y defendía un rol docente de ese tipo. Por esto, la CMOPE ayudó a difundir el imaginario de la profesionalización docente, que sean los profesores quienes toman las decisiones pedagógicas, superando el rol técnico. Esto estaba en estricta sintonía con las posiciones defendidas por El Pizarrón desde sus orígenes.

La revista recalcó que la dictadura había provocado una desprofesionalización de la labor docente, más allá de algunas medidas simbólicas (creación del CP, traspaso de las Escuelas Normales a las Universidades, etc.), pero que de todas formas persistía algo del gradual proceso de profesionalización previo a 1973. En ese sentido, la búsqueda de una profesionalización era polisémica, pues los docentes se consideraban trabajadores asalariados, pero desempeñando funciones específicas, aunque no reconocidas como tal y carentes de autonomía (El Pizarrón, $\mathrm{n}^{\circ}$ 46, 1987).

Muy en sintonía con la CMOPE, El Pizarrón vio en la elección de una conducción opositora en el CP como la posibilidad de provocar un giro histórico en las organizaciones del magisterio chileno. A pesar de reconocer que los profesores eran "trabajadores asalariados" ( $E l$ Pizarrón, $\left.\mathrm{n}^{\circ} 13,1981\right)$ y no una "profesión liberal", estos poseían una formación especializada, por lo que "la gran mayoría del magisterio se asume más que como simple trabajador, como profesional de la educación" (El Pizarrón, n 37, 1986). Esto último los llevaba a considerar que una organización profesional era la que le haría sentido al grueso del profesorado, dejando atrás el carácter exclusivamente reivindicativo. Pero la masividad del CP no era voluntaria, el profesorado estaba afiliado a él debido a que hasta 1981 era obligatorio para ejercer la docencia y desafiliarse o pertenecer a la AGECH era reconocerse públicamente como opositor a la dictadura. Por otro lado, la masividad de una asociación tradicionalmente se logra por motivaciones laborales o económicas, mientras que la renovación pedagógica históricamente ha reunido a sectores minoritarios, y en esa época no fue la excepción. Además, el magisterio durante los '80s cuestionó si realmente ejercía un rol profesional, pues su actividad estaba altamente controlada por el régimen y sus condiciones eran precarias, difícilmente asimilables a las capas medias (Adler y Melnick, 1998), siendo más plausible la aceptación de su proletarización y su carácter asalariado, con una condición legal muy similar a las clases trabajadoras.

De esta forma, El Pizarrón en marzo de 1986 defendió la idea de "dejar atrás el forzado modelo del sindicalismo (...) [y] asumir la condición de gremio profesional, (...) asumir 
honestamente la pertenencia a la clase media (...) Hoy en día no se necesita identificarse con el proletariado para defender el futuro democrático de Chile" (El Pizarrón, $\mathrm{n}^{\circ}$ 37, 1986). Esto último se justificaba, en una visión compartida por el socialismo renovado y la DC, en la importancia de los sectores medios profesionales para la lucha contra la dictadura. Lo anterior se apreció una vez asumida la nueva conducción del CP, la que intentó afiliar a éste a la Federación de Colegios Profesionales, iniciativa fallida y desechada en 1988, cuando el CP, a despecho de los presagios de El Pizarrón en su número 37, de marzo-abril de 1986, se hizo parte activa de la fundación de la Central Unitaria de Trabajadores.

Tal como ha ido estudiado recientemente (Reyes, 2021), la idea de formar un colegio profesional era una vieja aspiración de sectores católicos de profesores egresados del Instituto Pedagógico, identificados con la línea más derechista de la DC. Pero los variados intentos de conformar dicha entidad fueron impedidos por la oposición de diversos sectores políticos, incluidos la mayoría de la DC y por supuesto los socialistas. Pero en los '80s, la renovación política llevada a cabo al interior del socialismo permitió revalorar a esa estructura, sustentada en un giro hacia el centro de antiguos maximalistas de la izquierda como Iván Núñez, quienes bajo acusaciones de vanguardismo y sectarismo hacia la AGECH estaban dispuestos a defender los antiguos proyectos rechazados y que ahora eran recibidos como herencia de la dictadura.

El triunfo del sector conducido por la DC en el Colegio abrió nuevas posibilidades para el desarrollo de temáticas educativas. En esto fue vital el respaldo de la CMOPE y del PIIE, mediante recursos financieros e investigadores, varios de ellos provenientes de El Pizarrón, como Ricardo Hevia, que en 1986 asumió como director del recién creado Instituto de Perfeccionamiento del CP. En esa línea, la influencia de la revista fue notoria. En cambio, el CP fue incapaz de enfrentar los últimos traspasos de escuelas desde el Estado a los municipios. Si bien la unidad en la acción entre la AGECH y el Colegio permitió la primera movilización docente realmente de masas durante la dictadura, en esta se hizo casi imperceptible las diferencias entre el número de asociados de ambas organizaciones (Matamoros y Álvarez, 2020). Parte importante de las prácticas asociadas al Movimiento de Renovación Pedagógica con las que la revista se identificó buscaron ser continuadas por el mencionado Instituto de Perfeccionamiento (Guzmán, Barría, Peñafiel, y Aránguiz, 1989). En invierno y luego en octubre de 1986 se desarrollaron temporadas de perfeccionamientos con 20 cursos presenciales y 16 a distancia, enfocados en temáticas pedagógicas, de las asignaturas escolares, políticas educacionales, y administración educacional, quedando curiosamente el área gremial ausente.

Un carácter más masivo lograron estas iniciativas en enero de 1987, con la realización de la primera Escuela de Verano del CP. Allí, bajo la consigna de "Una escuela para la democracia" participaron cerca de dos mil profesores en los diversos cursos, los que fueron complementados con foros, seminarios, exposiciones y exhibiciones de videos. En los restantes veranos, hasta 1990, se llevaron a cabo nuevas escuelas, con las que se buscó contribuir a la transformación de las prácticas pedagógicas y el rol docente, como condición para el cambio educativo y la superación del autoritarismo educacional. Esos objetivos, luego profundizados con los Talleres de Educación Democrática (Reyes, 2005), serían vitales para alcanzar un rol profesional del profesor y se presentaban como un anticipo de cómo debiese ser una escuela en democracia, con plenas libertades y diversas metodologías no impositivas.

A pesar de que esas actividades no fueron gratuitas, contaron con una alta participación, lo que permitía pensar en que podrían potenciarse en un gobierno democrático. No obstante, no lograron una articulación adecuada con las prácticas más comunes de las organizaciones 
docentes. Precisamente en el verano de 1987 ocho mil profesores del país fueron exonerados, y las movilizaciones por esa medida no tuvieron conexión con las instancias de perfeccionamiento.

\section{Descentralización, repliegue del Estado y participación comunitaria}

Varios de los debates analizados se tradujeron también en la discusión sobre políticas educativas, donde la municipalización de los establecimientos ocupó numerosas páginas de la revista. Frente a los primeros y acelerados traspasos de escuelas a los municipios, entre 19801982, El Pizarrón fue sumamente crítico por el sentido mercantilizador de esa política, principalmente por haber privatizado los conflictos laborales e impuesto un manejo economicista de los problemas educativos (El Pizarrón, n $^{\circ} 37,1986$ ).

Pero a mediados de la década esa crítica empezó a matizarse. Desde 1984 en adelante varios de los integrantes de la revista consideraban que la municipalización no era negativa en sí misma, sino que carecía de condiciones de participación y autonomía municipal, las que eran imposibles de lograr bajo dictadura. En un artículo de marzo de 1986 se explicitó esta posición:

la idea de descentralizar la gestión educacional no es mala, al contrario; el problema es que [...] En las actuales condiciones políticas, económicas, sociales y culturales de nuestro país, la Municipalización, además de haber sido mal implementada, ha significado agudizar las contradicciones sociales en el área de la Educación, en desmedro de los grupos más pobres. (El Pizarrón, n³7, 1986)

Ricardo Hevia recuerda que por lo general era él quien escribía los temas relativos a descentralización en la revista, pues contaba con la experiencia de haber desarrollado estudios sobre municipalización en el PIIE (Entrevista 12 de octubre de 2021). Estas ideas no solo se sostuvieron en las páginas de El Pizarrón, sino también en diversas instancias donde los integrantes entregaban su parecer en cuanto especialistas en educación como por ejemplo el Seminario realizado por el CIDE a fines de 1984, donde Núñez declaró: "yo quisiera declararme fanático de la municipalización" (Cox, 1985), pues, a diferencia que la administración estatal, se estaba un paso más cerca de la participación de la comunidad en las decisiones educativas.

La revista, al igual que la conducción del Colegio evitó llamar al proceso de traspaso de escuelas a los municipios como descentralización o municipalización, más bien habló de una "alcaldización" (El Pizarrón, n³7, 1986), término que apareció por primera vez en un libro de 1984 coordinado por Ernesto Schiefelbein y Viterbo Apablaza. En otras ocasiones se señaló que la municipalización no representaba una "descentralización sino apenas una dudosa desconcentración administrativa" (El Pizarrón, $\mathrm{n}^{\circ}$ 40, 1986), pues los alcaldes administraban los establecimientos de acuerdo con las decisiones del "nivel central" (Ministerio del Interior), quien sería el órgano de decisiones presupuestarias y de administración de personal.

En 1989 un artículo titulado “¿Hubo descentralización antes de Pinochet?” daba cuenta de diversas experiencias de descentralización a lo largo de la historia, señalando que "a pesar del discurso descentralizador de la dictadura y de sus prácticas de desconcentración privatizante, como la mal llamada "municipalización", y de sus tímidos avances en materia de flexibilidad curricular, estamos en presencia de un sistema que ha concentrado el poder educacional como nunca antes en nuestra historia" (El Pizarrón, $\mathrm{n}^{\circ}$ 53, 1989). 
La mirada crítica hacia el traspaso de escuelas sin participación de la comunidad se distanciaba de aquella que era hegemónica en el magisterio, la que apelaba a una vuelta a la administración estatal. El Pizarrón consideró que estos eran razonamientos "apresurados", ya que significaba aceptar perpetuar la burocracia y la deformación autoritaria de un posible proyecto socialista. Por el contrario, se planteaba una perspectiva de "profundización socialista de la democracia. No de cualquier socialismo. No del que identifica socialismo con estatismo (...) Sí de un socialismo humanista y de participación popular" (El Pizarrón, $\left.\mathrm{n}^{\circ} 40,1986\right)$. Esto requirió de un revisionismo histórico respecto al rol jugado por el Estado en la educación, donde éste, como gigantesco aparato público, no tenía en cuenta las particularidades derivadas del desarrollo desigual de la sociedad chilena. De ahí vino el constante rescate de experiencias de descentralización y participación, como los Planes San Carlos y Arica, las Escuelas Consolidadas o inclusive la ENU (Escuela Nacional Unificada), la que habría estado en una línea similar a la municipalización, pero sin los marcos neoliberales y autoritarios.

Tal como la revista lo reconoció ya desde 1981, en el artículo "El pensamiento de Friedman sobre educación", sus críticas al estatismo, su burocracia y centralización, le hacían compartir varias posiciones con las ideas del neoliberalismo. Pero se distanciaban en el fomento a la privatización, proponiendo en cambio la participación de la comunidad en la gestión educativa (El Pizarrón, $\left.\mathrm{n}^{\circ} 13,1981\right)$. Esto también les hizo valorar algunos aspectos de las posiciones de Gonzalo Vial, ex ministro de Educación de la dictadura durante 1979, periodo en que precisamente se dictó la Directiva Presidencial de Educación, que dio curso al inicio de las reformas neoliberales. El Pizarrón, en marzo de 1984, compartía la idea de Vial respecto a que la educación siempre es una cuestión pública, con lo cual esta no debía estar limitada:

única o monopólicamente al aparato del Estado, a su institucionalización gubernamental. Pensamos en la acepción amplia de Estado, como comunidad organizada de participantes y no como burocracia autoafirmada. Más bien, pensamos en recuperación de la responsabilidad social en educación, responsabilidad que admite y exige la participación de las comunidades locales, los grupos funcionales, las familias y las personas mismas. (El Pizarrón, $\mathrm{n}^{\circ}$ 27, 1984)

A estas alturas era inexistente algún tipo de comprensión del Estado en términos marxistas, en el sentido del carácter de clase que este representa. Se defendía más bien una comprensión funcionalista, donde la sociedad es entendida como cuerpo donde cada una de sus partes cumple una determinada función, representando el Estado a esa comunidad organizada de participantes.

También existía concordancia con Gonzalo Vial respecto a admitir el "fracaso del sector privado", pero desde la revista se replicaba que aquello no quiere decir que las fuerzas sociales no se interesan por la educación o que son incapaces de asumir su responsabilidad, independiente de que requieran apoyo del Estado para financiamiento, formación, perfeccionamiento, apoyo técnico y material, y en objetivos educacionales compartidos por toda la nación. Tal fracaso tampoco debería llevar de regreso "la responsabilidad educativa en beneficio de un Estado burocrático y centralizado". Como vemos para El Pizarrón, cuando el Estado administra la educación, casi por naturaleza, tiene un carácter burocrático y centralizado, olvidando el hecho de que todas las experiencias de descentralización previas, rescatadas en sus mismas páginas, se produjeron al alero del Estado. 
En cambio, donde la revista se distanciaba completamente de Vial era respecto a las características de la educación "masiva", la que debía alejarse de las miradas iluministas, y, en cambio, debía apoyar y robustecer la propia cultura popular y su identidad de pueblo y clases, fortaleciendo la organización popular, cuyo sujeto activo no son las élites, ni el intermediario mesocrático, sino las propias masas populares. En definitiva, la educación de masas debiese ser una educación autogestionada por las masas mismas, de las que el propio magisterio debía ser parte por origen social, adhesión o asimilación.

Estos posicionamientos de la revista sobre el rol del Estado no eran mayormente compartidos por el profesorado, ni oficialista ni opositor. Respecto de este último, en un artículo de marzo de 1984, llamado "Las subvenciones en el banquillo", se criticó a quienes deseaban reinstaurar la concepción de Estado docente previa a 1973:

escuchamos a menudo que es un imperativo que el Estado vuelva a tomar en sus manos el control de las escuelas municipalizadas y particulares subvencionadas [...] volver al esquema de un Estado que asuma en sus propias manos la ineludible responsabilidad de impartir por sí mismo, la educación que nuestros niños y jóvenes necesitan. ( $E l$ Pizarrón, $\left.\mathrm{n}^{\circ} 27,1984\right)$

Frente a ese ideario estatista del magisterio, la revista planteó en cambio:

del todo urgente cuestionarnos sobre la validez de esta concepción [...] La pregunta sería si es efectivamente condición necesaria de una educación democrática el que el Estado asuma por sí mismo la responsabilidad directa de impartir la educación [...] la estructura de un Estado Docente tal cual la vivimos, no asegura, en el fondo, una estructura democrática y participativa en la gestión educacional. Más bien la creemos un impedimento para un ejercicio auténticamente democrático de la labor educativa que corresponde a la comunidad organizada en función de otorgar el servicio educativo que ella necesita. Creemos que el Estado al asumir por sí mismo toda la labor educacional del país más bien le expropia a la comunidad la responsabilidad de asumir el deber de pensar y llevar a cabo una función social que le corresponde. (El Pizarrón, n 27, 1984)

La función social pareciera ser una suerte de propiedad inherente de la comunidad, sin la cual era imposible "una verdadera renovación de la escuela chilena", donde el Estado se debiese limitar a asegurar las condiciones democráticas para que la comunidad ejerza su responsabilidad. Entre esas condiciones estaba el permitir una subvención a particulares organizados en comunidades educativas que aseguren la calidad de la educación. Sobre este punto, El Pizarrón tomaba como referente un proyecto del gobierno socialdemócrata español, el PSOE de Felipe González, el que permitía la subvención educacional a particulares a condición de que las escuelas creadas se organicen efectivamente en una comunidad educativa donde los diversos actores asuman su responsabilidad en la gestión escolar. De esta forma, se defendió la idea de una subvención a privados en un contexto de gestión social de la educación, con lo cual la subvención jugaría un rol más eficaz en la democratización educacional.

El repliegue del Estado dejaría a este con un rol orientador y de apoyo a la tarea educativa, pero no asumiendo la propiedad, administración, ejecución, ni el monopolio del cambio educativo (El Pizarrón, $\mathrm{n}^{\circ}$ 40,1986). Nuevamente acá aparecen las similitudes con las ideas del neoliberalismo, donde el principio de subsidiariedad, defendido por este, precisamente 
apelaba a la participación de las entidades intermedias, especialmente las familias, en la administración escolar (Cristi, 2011).

Estas críticas a las posiciones "estadocéntricas", centrales del discurso renovador, también eran deudoras del llamado "socialismo utópico", de tradición europea, donde las comunidades generaban prácticas de apoyo mutuo sin la necesidad de la "toma" del Estado. Sin embargo, en el contexto planteado por El Pizarrón, la participación de las comunidades se veía amenazada por los intereses privados, donde el repliegue estatal no implicaba inmediatamente una mayor injerencia de los sectores populares, dejando el campo abierto para la libertad de empresa.

Esto estaba en sintonía con el proceso de renovación política. En un artículo llamado "Municipalización: Desafío para la futura democracia" se planteó que bajo un gobierno democrático debiese existir un amplio consenso político e ideológico para garantizar en términos de estructura social, por un lado, la subsistencia de la propiedad privada de los medios de producción, y en el ámbito educativo, la existencia de las entidades privadas de educación, en virtud del respeto del precepto de libertad de enseñanza (El Pizarrón, $\mathrm{n}^{\circ}$ 40, 1986).

Tal como ha señalado Sebastián Neut, al estudiar al PIIE y al CIDE en este periodo, el pragmatismo que estas entidades adoptaron durante la transición "se tradujo en depreciar el rol rector y administrador del Estado en el campo y relevar como contraparte el de los privados y de la sociedad civil. Por lo mismo, permitió ponderar como (potencialmente) positivas varias de las políticas implementadas por la Dictadura" (Neut, 2018, p. 200). El análisis de El Pizarrón reafirma esa evaluación.

\section{Llega la "alegría": se borra El Pizarrón}

En los últimos números de la revista se aprecia el intento por entregar propuestas para las futuras políticas públicas, las que no debían partir de cero, sino que reconocer como punto de inicio las políticas implementadas por la dictadura desde 1979 en adelante. A pesar de que estas tenían numerosos reparos, no se debía volver a la situación previa a 1973. Había que asumir la municipalización y no ignorarla, dejando la responsabilidad de cambio al futuro gobierno democrático, el que debía terminar con el manejo autoritario y economicista de los alcaldes. Era la táctica de los "hechos consumados", asumida por la oposición moderada a la dictadura, la que venía fraguando un consenso educativo con sectores oficialistas desde 1984 (Cox, 1985). Allí radica el sustento de la profundización del Estado subsidiario durante los gobiernos posdictatoriales.

En el número 53, de junio-julio de 1989 se anunció que la revista pasó a contar con el patrocinio institucional del PIIE, aunque la responsabilidad continuaba bajo el núcleo editorial. Lo anterior, junto al inminente inicio de un gobierno democráticamente electo, llevó a que los últimos números presentaran un lenguaje mucho más mesurado, neutro y "responsable", prefigurando lo que serían las políticas educacionales de los gobiernos de la Concertación. De esta forma, se hicieron comunes en sus páginas conceptos como alcaldización, calidad y equidad. El tema de la calidad de la educación se transformó en uno de los predominantes en las discusiones que se dieron en el PIIE y el CIDE durante la segunda mitad de los '80s (García Huidobro, 1989). La revista no presentó una mirada inquisitiva sobre qué se entendía por calidad, sino que más bien asumió que esta era posible apreciarla por los resultados en la principal prueba estandarizada que inició su aplicación en ese periodo, el Sistema de Medición de la Calidad de la 
Calidad de la Educación (SIMCE), cuestión distinta a lo que se señalaba en 1984 cuando se diferenciaba que la calidad no podía referirse solo a "logros instruccionales" (El Pizarrón, n 27 , 1984).

Si bien desde El Pizarrón se planteó persistentemente que la calidad era más deficitaria en los sectores populares, por lo tanto se conjugaba con la equidad, y allí debían focalizarse los esfuerzos, apuntando a las raíces teóricas y estructurales del sistema, no consideró que precisamente una evaluación estandarizada reforzaría las brechas de equidad y una vez impuesto los resultados del SIMCE como el referente único de la calidad, su carácter estandarizado terminaría jugando en contra de la educación de los sectores populares. A pesar de reconocer que los resultados del SIMCE no era la única forma de evaluar la calidad, "al menos permiten demostrar objetivamente la calidad de la enseñanza" (El Pizarrón, n 53, 1989).

De esta forma, en la citada edición de mediados de 1989 el número de temáticas se redujo y aparecen títulos más apropiados para políticas institucionales específicas: "Mujer y educación: Todas íbamos a ser reinas", "Políticas para la educción parvularia: Un tema olvidado", "El analfabetismo en Chile: Un problema no superado", "Calidad de la Educación Básica: SIMCEramente mala". Junto a la calidad, una preocupación fundamental fue la de los recursos económicos para desarrollar dichas políticas, asumiendo ya una preocupación como parte la próxima administración, anticipando lo que sería característico durante el gobierno de Aylwin, la priorización de esas políticas y su financiamiento hacia sectores empobrecidos.

Por otro lado, se mantuvo la preocupación por la participación de las comunidades, lo que debía estar presente, por ejemplo, en la educación parvularia y en los procesos de alfabetización y educación de adultos, donde se propuso propiciar la participación social, incorporando en el proceso de aprendizaje, la cultura y el saber popular. Esta participación de comunidades imaginarias, y no imaginadas, sería la condición de posibilidad de la intervención estatal, la ausencia de estas y de un rol más activo del Estado, daría cuenta de que, por omisión tal vez, estos planteamientos dejaban abierta la puerta al ingreso de privados a nuevos ámbitos del sistema educacional.

Ha sido un fenómeno destacado cómo la llegada de los gobiernos posdictatoriales pusieron fin a la importante cultura opositora, materializada en diversas publicaciones, especialmente revistas y periódicos. Esta misma situación ocurrió con El Pizarrón. Los integrantes de esta revista coinciden en señalar que el cierre de la publicación se debió al paso de los integrantes a asumir cargos institucionales en el nuevo gobierno civil. Ya desde 1989 Rodrigo Vera se concentró en su trabajo en la UNESCO, mientras que en marzo de 1990 los restantes tres integrantes del núcleo intelectual de El Pizarrón pasaron a ser parte del Ministerio de Educación dirigido por Ricardo Lagos. Iván Núñez asumió como encargado del Ministerio en las relaciones con el magisterio, Ricardo Hevia como encargado de las relaciones internacionales y Eduardo Castro como asesor del ministro. Colabores de la revista también se sumaron al gobierno. Carlos Eugenio Beca asumió como jefe de Gabinete del ministro Lagos y Gabriela Pishedda pasó a trabajar al recién creado Servicio Nacional de la Mujer. Hevia señala que:

teníamos esperanza en que varias de las cosas que habíamos dicho por años ahora la íbamos a poder realizar desde el Estado. Decidimos de forma colectiva que no tenía sentido seguir con la misma lógica, ahora teníamos que ser propositivos desde adentro. Ya se había ganado el Colegio de Profesores. Se había ganado la democracia. Las reformas iban a venir, eso esperábamos. (Entrevista 12 de octubre de 2021) 
Desde esos cargos, intentaron aportar con el conocimiento producido durante la última década, adoptando un rol intelectual de experto o tecnócrata. Pero sus resultados han sido objeto de diversos análisis críticos, por sus mínimos avances, por la profundización del modelo neoliberal y por los escasos espacios abiertos a la participación, especialmente de docentes y estudiantes, representando no una superación del viejo "sectarismo" de las organizaciones de izquierda, sino su reemplazo mediante la imposición del "nuevo sectarismo" concertacionista. Allí la función intelectual abandonó cualquier rasgo "basista" vinculada a las organizaciones sociales, para adoptar el carácter de "experto" que colabora con los actores políticos institucionales (Moyano y Lozoya, 2019).

Rodrigo Vera reafirma este juicio, señalando que "uno de los pecados de la Concertación, en sus 30 años, fue haber despreciado la participación, pues se entendía que sólo existía política al interior del Estado y fuera de este no había participación" (Entrevista, 27 de septiembre de 2021).

\section{Conclusiones}

La revista El Pizarrón fue la publicación educativa opositora dirigida al magisterio más importante y permanente durante la dictadura militar. Su vinculación con la producción intelectual opositora y con las organizaciones docentes le llevó a ser un importante referente para comprender la renovación de los postulados educativos de los sectores de la izquierda chilena que pasaron a ser gobierno en la postdictadura y para analizar la persistencia de las políticas impuestas en dictadura.

Las ideas de renovación pedagógica venían siendo sostenidas por algunos integrantes de la revista desde fines de los '60s, pero durante la dictadura esas ideas fueron resignificadas, especialmente por el proceso de renovación política en el cual los intelectuales de El Pizarrón se insertaron, alejándose completamente de la posibilidad de desarrollar una renovación pedagógica al alero del Estado.

Tal posicionamiento no tuvo una importante acogida en el magisterio, salvo en el democratacristiano, ni siquiera en el identificado con el socialismo, pues el sector docente que adhirió al proceso de renovación política fue minoritario, mientras que el profesorado almeydista solo las asumió en tiempos posdictatoriales (Matamoros, 2019). Sectores del magisterio identificados con el radicalismo o el comunismo continuaron manteniendo sus visiones estatistas durante varios años después de la llegada de la Concertación al gobierno, cosmovisión que sigue estando asentada en el grueso del profesorado chileno.

La renovación desarrollada en la revista estuvo en estricta sintonía con el proceso de renovación política que experimentó el socialismo chileno durante la década. La proyección del proceso de renovación hacia los gobiernos posdictatoriales tuvo en la figura de Iván Núñez su ejemplo más representativo, principalmente por su rol respecto a las organizaciones del magisterio. Jorge Pavez, destacado dirigente docente, recuerda la situación durante 1990-1991:

el caso más paradigmático fue la respuesta que obtuvimos a nuestra propuesta de Estatuto Docente. Su negociación en mesa técnica curiosamente enfrentó a la dirigencia del Colegio con quienes habían sido los gestores y asesores técnicos que había elaborado 
los aspectos centrales de nuestro Estatuto, y que observábamos ahora cómo defendían posiciones enmarcadas en la obsecuencia al marco privatizador definido. (Pavez, 2010)

Lo anterior da cuenta de que la participación de las comunidades, defendida por la revista durante toda su historia, terminó siendo excluida en la postdictadura, no así el otro componente eje de la renovación educativa y política: el repliegue del Estado. Este último, sin participación de las comunidades, se tradujo en una apertura radical al ingreso de la empresa privada a la administración educativa, profundizando el modelo neoliberal mediante la consolidación del proceso de renovación política desarrollado por el socialismo chileno.

Si el objetivo del proceso de renovación analizado no fue acogido con éxito en el profesorado, por la persistencia de las visiones estatistas, esto no ocurrió a nivel de las élites partidarias que ejercieron cargos de gobierno en la postdictadura, por lo que nuevas investigaciones sobre la producción académica de los integrantes de El Pizarrón pueden arrojar luces respecto al éxito de su rol intelectual más de tipo "experto", que al rol autoasignado en la revista en una dinámica de "investigación-acción" vinculado a las organizaciones sociales.

\section{Bibliografía}

Adler, L. y Melnick, A. (1998). Neoliberalismo y clase media: el caso de los profesores de Chile. Santiago: DIBAM.

Caiceo, J. (2021). Anales de la Facultad de Educación de la Pontificia Universidad Católica de

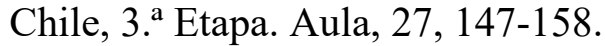

Celis, L. (coord.) (1982). La presencia de la filosofía en la Universidad Católica (1888-1973). Anales de la Escuela de Educación, 5, Tercera Época.

Cerda, A., Silva, M. y Núñez, I. (1991). El sistema escolar y la profesión docente. Santiago: PIIE.

Cisterna, P. (2019). Memorias de un pizarrón. Reivindicando la AGECH. Provincia de Concepción. 1981-1987. Santiago: s/e.

Cox, C. (editor) (1985). Hacia la elaboración de consensos en política educacional: actas de una discusión. Santiago: CIDE.

Cristi, R. (2011). El pensamiento político de Jaime Guzmán: una biografía intelectual. Santiago: Lom.

Darnton, R. (2010). El beso de Lamourette. Reflexiones sobre historia cultural. Buenos Aires: Fondo de Cultura Económica.

Espinoza, O. y González, L.E. (1993). La experiencia del proceso de desconcentración y descentralización educacional en Chile, 1974-1989. Santiago: Documentos PIIE.

Esteban, S. (2016). La renovación pedagógica en España: un movimiento social más allá del didactismo. Tendencias Pedagógicas, 27, 259-284.

García Huidobro, J.E. (1989). Escuela, calidad e igualdad. Los desafíos para educar en democracia. Santiago: CIDE. 
Guzmán, I., Barría, J., Peñafiel, S. y Aránguiz, G. (1989). Movimientos de Renovación Pedagógica y de Estímulo a la Innovación. En PIIE, Educación y transición democrática. Propuestas de políticas educacionales (pp. 149-157). Santiago: PIIE.

Hernández, J. (Ed.) (2013). Prensa pedagógica y patrimonio histórico educativo. Contribuciones desde la Europa mediterránea e Iberoamérica. Salamanca: Ediciones Universidad de Salamanca.

Hernández, R., Zamorano, L. (2016). El pensamiento y acción social en el profesorado de regiones en la época del primer gobierno de Arturo Alessandri (1919-1925): el caso del profesorado primario de Ancud. En: B. Silva (Compilador), Historia social de la educación chilena. Tomo 2. Instalación, auge y crisis de la reforma alemana. 1880-1920. Pensamiento, pensadores y demandas educativas (pp. 98-120). Santiago: Ediciones Universidad Tecnológica Metropolitana.

Hernández, R. (2018). La Escuela Nueva: Chiloé. Una mirada insular 1919-1925. Revista Enfoques Educacionales, 15 (1), 47-60.

Hernández, B. (2018). Entre la educación, la instrucción y el ejercicio docente dentro del sistema educativo. Ideas de educadoras en registros de Revista de Instrucción Primaria en Chile entre 1898-1910. Revista Enfoques Educacionales, 15 (1), 4-27.

Martínez, R. (2020). Transferencias globales en la educación chilena: promoción del ideal democrático a través de la Revista de Educación de la Asociación de Educación Nacional (1905-1921). Cuadernos chilenos de Historia de la Educación, (13), 104-128.

Matamoros, C. (2019). La renovación en las aulas. Cambios y resistencias en los profesores socialistas chilenos. 1979-1993. En C. Matamoros (editor), Sindicalismo docente. Política y Organizaciones de Izquierda Sudamericana (pp. 101-166). Concepción: Ediciones Escaparate.

Matamoros, C. Álvarez, R. (2020). “No + Municipalización”. La resistencia docente a los traspasos de escuelas públicas. Chile. 1986, Izquierdas (49), 2146-2177.

Mejías, E. (2019). Creatividad, colaboración y humor: producción y circulación de revistas escolares en Chile entre 1920 y 1938. Bajo la Lupa, Subdirección de Investigación, Servicio Nacional del Patrimonio Cultural.

Moyano, C. (2009). Los líderes de la izquierda. Configuración de las elites en el imaginario político chileno dictatorial y el rol de las revistas políticas de oposición, 1973-1989. Bicentenario: revista de historia de Chile y de América. 8 (1), 55-86.

Moyano, C., Mella, M. (2018). La Revista Proposiciones: espacio de sociabilidad intelectual y producción de saberes en el campo intelectual de la izquierda chilena durante los años 80. Revista Austral de Ciencias sociales, (32), 77-88.

Moyano, C. Lozoya, I. (2019). "Intelectuales de izquierda en Chile”: ¿de la politización a la tecnocracia? Debates sobre la función política y el ser del intelectual entre 1960 y 1990. Signos Históricos. XXI (41), 192-229.

Muñoz, C. (2015). Prensa de oposición en dictadura. La revista APSI como plataforma discursiva de la renovación socialista. 1980-1988. Tesina para optar al grado de Licenciado en Historia, Universidad Academia de Humanismo Cristiano, Santiago.

Nervi, M. (2013). Iván Núñez Prieto. Trazos y huellas en la educación chilena del siglo XX. Santiago: Editorial Universitaria.

Neut, S. (2018). Prácticas y discurso intelectual en ONG's educacionales opositoras a la Dictadura chilena. Los casos del CIDE y PIIE. Izquierdas. (42), 198-223. 
Núñez, I. (1978). Revistas educacionales chilenas. Antecesoras de Cuadernos. Cuadernos de Educación, (77), 136-142.

. (1986a). Gremios del magisterio. Setenta años de historia: 1900-1970. Santiago: PIIE. (1990). Reformas institucionales e identidad de los docentes. Chile, 1960-1973. Santiago: PIIE. . (2013). Biología y educación: Los reformadores funcionalistas. Chile, 1931-1948. Cuadernos Chilenos de Historia de la Educación, (1), 65-86.

Orrego, P. (2002). Los reflejos de un espejo: Chile y el mundo, entre los años 1976 y 1989, a través de la revista APSI. Tesis para optar al grado de Licenciado en Historia, Pontificia Universidad Católica de Chile, Santiago.

Pavez, J. (2010). Un hombre en la multitud. Recuerdos de un luchador social. Santiago: Das Kapital ediciones.

Pita, A. y Grillo, M. (2015). Una propuesta de análisis para el estudio de revistas culturales. Revista Latinoamericana de Metodología de las Ciencias Sociales, 5 (1), 1-30.

Reyes, L. (2005). Movimientos de educadores y construcción de política educacional en Chile. (1921-1932 y 1977-1994). Tesis para optar al grado de Doctora en Historia, Universidad de Chiles, Santiago.

Reyes, R. (2021). Del proyecto a la disputa: continuidades y rupturas del magisterio demócrata cristiano en la construcción de un colegio profesional (1955-1985). REVUELTAS. Revista Chilena de Historia Social Popular, (4), 11-36.

Salinas (2017). Pensar la escuela desde la escuela para el cambio social: el rol histórico de las maestras primarias en la construcción de la educación popular estatal (1927-1953). Tesis para optar al grado de Doctora en Historia. Universidad de Chile, Santiago.

Santoni, A. (2013). Modelos y antimodelos de la renovación socialista. La revista "Convergencia" y la crisis del socialismo mundial (1981-1991). Historia. I (46), 153176.

Silva, B. (2016). De madres civilizadoras a defensoras del derecho a educarse de los más pobres. Críticas y demandas de educadoras en la Revista de Instrucción Primaria durante la instalación y auge de la reforma alemana. Chile 1887-1901. En B. Silva, (compilador), Historia social de la educación chilena. Tomo 2. Instalación, auge y crisis de la reforma alemana. 1880-1920. Pensamiento, pensadores y demandas educativas. Santiago: Ediciones Universidad Tecnológica Metropolitana. . Silva, B. (2017). Debatir, transformar, educar y proteger: postulados de educadoras en la Revista de Instrucción Primaria (Chile, 1902-1910). En Silva, B. (compilador), Historia social de la educación chilena. Tomo 3. Instalación, auge y crisis de la reforma alemana. 1880-1920. Estudios finales (pp. 196-248). Santiago: Ediciones Universidad Tecnológica Metropolitana.

Silva, C. (2010). "Para cada profesor, una revista". La Revista de Educación y la formación de docente en Chile. 1965-1970. Revista Pensamiento Educativo, (46-47), 187-203.

Tarcus, H. (2004). Revistas, intelectuales y formaciones culturales izquierdistas en la Argentina de los veinte. Revista Iberoamericana. LXX (208-209), 749-772.

Valenzuela, E. (2011). Cristianismo, revolución y renovación en Chile: El Movimiento de Acción Popular Unitaria (MAPU), 1969-1989. Tesis doctoral, Universitat de Valéncia.

Vera. R. (1972). Acerca de las bases para una política de perfeccionamiento. Revista de Educación, (43-46), 99-104. 


\section{Revistas}

El Pizarrón, 1979-1990.

\section{Entrevistas}

Rodrigo Vera Godoy, 27 de septiembre de 2021.

Ricardo Hevia Rivas, 12 de octubre de 2021.

Jorge Olivo Lillo, 27 de julio de 2018.

José Letelier, 28 de junio de 2017.

Guillermo Scherping, 25 de enero 2016. 